\title{
₹USGS
}

\section{Evaluation of airborne}

image data and LIDAR main stem data for monitoring physical resources within the

\section{Colorado River ecosystem}

by Philip A. Davis ${ }^{1}$,

Mark R. Rosiek ${ }^{1}$, and

Donna M. Galuszka ${ }^{1}$

Open-File Report 02-469

2002

This report is preliminary and has not been reviewed for conformity with U.S. Geological Survey editorial standards or with the North American Stratigraphic Code. Any use of trade, firm, or product names is for descriptive purposes only and does not imply endorsement by the U.S. Government.

U.S. DEPARTMENT OF THE INTERIOR

U.S. GEOLOGICAL SURVEY

${ }^{1}$ Flagstaff, Arizona 


\begin{abstract}
This study evaluated near-infrared LIDAR data acquired over the main-stem channel at four long-term monitoring sites within the Colorado River ecosystem (CRE) to determine the ability of these data to provide reliable indications in changes in water elevation over time. Our results indicate that there is a good correlation between the LIDAR water-surface elevations and ground measurements of water-edge elevation, but there are also inherent errors in the LIDAR data. The elevation errors amount to about $50 \mathrm{~cm}$ and therefore temporal changes in watersurface elevation that exceed this value by the majority of data at a particular location can be deemed significant or real.

This study also evaluated airborne image data for producing photogrammetric elevation data and for automated mapping of sand bars and debris flows within the CRE. The photogrammetric analyses show that spatial resolutions of $\leq 10 \mathrm{~cm}$ are required to produce vertical accuracies $<20 \mathrm{~cm}$ and that digitally acquired data cannot yet support this monitoring requirement. The mapping analyses indicate that CIR image data are far superior to true-color and panchromatic image data in mapping sand bars and debris flows. The analyses also show that the CIR color information provide almost as much mapping capability as do the combination of CIR color and CIR image texture. Therefore, CIR image data should always be given preference in image data collections, not only for the physical resource program, but also for the biologic resource program.
\end{abstract}

\title{
Introduction
}

The Physical Resource Program within the Grand Canyon Monitoring and Research Center (GCMRC) of the U.S. Geological Survey (USGS) monitors the effects of the Glen Canyon Dam's flow rate on the geologic resources located within the Colorado River ecosystem (CRE) in Arizona. These resources include unconsolidated, fine-grained sand bars, coarse-grained debris flows, and more consolidated river terrace deposits. Most attention is given to the sand bars and debris flows in proximity to the river because they are more directly affected by river flow. Both land and channel sediment deposits are periodically mapped to determine sediment distribution and volume to constrain flow scenarios (models) that try to preserve these resources. For a few decades, the primary mode for monitoring the land sediments has been a combination of field and photographic interpretations and measurements. The photographic data to support the terrestrial monitoring were collected on film at very high spatial resolution $(1: 4,800$ scale that provides a maximum $6 \mathrm{~cm}$ resolution) and were only converted to digital form under certain circumstances. During the past two years, a variety of analog and digital image data and LIDAR data have been collected to determine the most appropriate remote-sensing data for different GCMRC program objectives.

The LIDAR data that were collected have been evaluated for mapping topography and estimating volume for sand bars on land. Overall, it was found to be inferior to photogrammetry for vegetated terrain when the spot spacings are greater than or equal to $1.5 \mathrm{~m}$ (Davis et al., 2002). However, scientists in the Water Resources Division of the USGS recently noticed a close correspondence between average LIDAR elevations (acquired in March 2000) over the main stem channel and historical (early 1900's) ground measurements of water surface elevations. They also noticed that at certain locations along the main stem, the recent LIDAR elevations were higher than the historical water-surface profiles by more than one meter. The locations of some 
of the larger elevation differences coincide with known, young debris flows. This coincidence suggests that the LIDAR data could be used to detect debris flow changes in the CRE that have occurred since the early 1900's, when the historical measurements were performed. Although this is a not a common application of LIDAR data, the SHAOLS LIDAR instrument does use a near-infrared laser to determine the elevation of the water's surface in deriving bathymetry (Irish and Lillycrop, 1999). The Water Resources scientists used the low-resolution (3.75-m spot spacing), near-infrared LIDAR data for their comparison because those data were acquired (in March 2000) for the entire CRE and therefore allow a system-wide analysis. However, these data were found to have relatively low vertical accuracies (generally $>50 \mathrm{~cm}$ ) on bare sand (Davis et al., 2002). Our present study examines the March 2000 LIDAR data over the main-stem channel at river reaches where ground-elevation surveys of the water's edge were performed during 2000 in order to address two issues related to the potential use of these LIDAR data for measuring water-surface elevation. The first issue is whether near-infrared LIDAR elevations on the main stem actually indicate the true elevation of the water surface. The second issue is whether the root-mean-square error (RMSE) in the LIDAR water-surface measurements is less than the elevation differences that are observed between the LIDAR elevations and the historical watersurface measurements. The root-mean-square error is a common measure of LIDAR accuracy. It is the square root of the average of the squared differences between the LIDAR and true-ground elevations.

The trend in current image data collections in GCMRC is toward digital image acquisition when possible, or at least scanning of collected film, in order to better preserve the data and to make it more accessible to the program scientists. Our previous studies of various image data for biologic resources showed the optimum data set to be calibrated, digital colorinfrared (CIR) imagery with spatial resolutions $\leq 20 \mathrm{~cm}$ (Davis et al., 2002). However, physical scientists monitor different resources than the biologic scientists and may have different image data requirements. Physical scientists use image data to map morphologic and morphometric changes in the sediment deposits within the CRE. Although image data at spatial resolutions near $20 \mathrm{~cm}$ can satisfy the morphologic mapping requirements of the physical scientists (Jack Schmidt, Utah State U., 2000, personal communication), conventional photogrammetric wisdom suggests that an image resolution near $6 \mathrm{~cm}$ is necessary to produce topographic data that meet the $20-\mathrm{cm}$ vertical accuracy required for monitoring the sediment deposits. Image resolution is initially determined by the camera lens and aircraft flight height above the ground and subsequently, if analog data are acquired, by the picture-element resolution used to scan the image film. The costs for both acquisition and scanning of image data increase with spatial resolution. Thus, this study examines the vertical accuracies obtained using imagery acquired at different ground resolutions and scanned at different picture-element resolutions to determine the lowest resolution imagery that provides acceptable elevation accuracies. Because photogrammetric requirements for ground resolution are usually more stringent than the spatial resolutions required for geomorphologic mapping, the results from the photogrammetric analyses will probably establish the effective ground resolutions required for both uses.

Photogrammetrists are divided as to the type of image data that is best for photogrammetry. Some photogrammetrists prefer black-and-white film because it is sharper than color film; others prefer color-infrared or true-color film because these data provide better discrimination between vegetation and shadows than black-and-white imagery. Thus, our evaluations also investigate the vertical accuracies provided by different types of image data. In addition, one of the goals for CRE monitoring is to map the distribution of sand bars and debris flows throughout the entire CRE on a periodic basis. Because of the $450 \mathrm{~km}$ extent of the CRE, it is preferable that this mapping be accomplished by rapid, efficient computer algorithms that can exclude vegetation from consideration and can recognize and map color (or brightness) and 
textural differences between sand bars and debris flows. We, therefore, investigate the ability of different types and spatial resolutions of image data for excluding vegetation, quantifying texture, and distinguishing brightness or color of sand bars and debris flows in order to inventory these resources throughout the $\mathrm{CRE}$ with cost-effective computer algorithms.

\section{Airborne Data and Study Areas Evaluated}

Our evaluation of LIDAR as a tool for obtaining corridor-wide water-surface profiles used the near-infrared LIDAR data acquired for the entire CRE during March 2000. The data were acquired at a spot spacing of 3.75 meters and a spot diameter of 1.0 meter using the Altimeter Laser Mapping System (ALMS) LIDAR system. In August 2000, ground survey crews measured the elevations of the water's edge and shoreline within four long-term monitoring reaches that are shown on Figure 1. Both data sets were acquired at a steady water-flow rate of $8,000 \mathrm{cfs}$ and are compared in this study.

Our evaluations of the image data for photogrammetric accuracy and for geomorphic analysis used three types of stereo image data. (1) $18-\mathrm{cm}$ digital panchromatic imagery acquired in August 2000 using a 4096 x 4096 charged-coupled device (CCD) array. (2) Color-infrared (CIR) photography acquired with a cartographic framing camera at 1:4,800 scale in July 2000 and scanned at 21 microns, resulting in a 10-cm ground resolution. (3) True-color photography acquired with a cartographic framing camera at 1:4,000 scale in August 2000 and scanned at 40, 20,15 , and 10 microns, resulting in digital images with ground resolutions of $16 \mathrm{~cm}, 8 \mathrm{~cm}, 6 \mathrm{~cm}$, and $4 \mathrm{~cm}$, respectively. The study area selected for this image analysis is located at river mile (RM) 43, just south of Eminence (Figure 1). This study area has sand bars separated by a large debris flow. Vegetation in this area consists of large, dense stands of tamarisk, scattered bushes, and scattered patches of grass. Ground control panels were placed along the river reach for the August flights; no panels were in place during the July image data collection. Ground-survey transects were performed on the sand bars and within adjacent vegetation stands during the August true-color image acquisition. These ground data are used to determine the vertical accuracies of photogrammetric data derived from the various stereo image data.

\section{Analyses and Results}

\section{LIDAR Accuracy for Measurement of Water-Surface Elevations}

At each of the four long-term monitoring sites (Figure 1), we constructed raster images of the LIDAR and ground-surveyed elevation data with a cell size of $25 \mathrm{~cm}$. At each site we also constructed a polygon of the water's extent. These water polygons were used to determine the directional trend of the water's edge at a particular ground survey location and to constrain the LIDAR analysis to water areas. Ground survey locations near riffles were excluded from this analysis because the LIDAR elevations at riffles are higher than the elevations at adjacent wateredge locations. We devised a computer algorithm that performed the following tasks within each study site. First, sequentially search from north to south the ground-survey elevation image for a surveyed elevation point. Second, determine a line orthogonal to the shoreline at that groundsurvey point that extended into the main stem for $50 \mathrm{~m}$. Third, extract average LIDAR elevations along that orthogonal line starting 5 meters from shore and ending at the line's terminus. The average LIDAR elevation along each water transect was recorded, along with its ground-survey elevation and location. The elevations and locations of these collected data within each river reach were then examined on the orthorectified panchromatic image base to determine if any points occurred at (1) sharp bends in the shoreline (such as eddies), which would produce a transect line that did not extend into the main stem, or (2) areas where the river width is less than the 50-m transect, which would result in data being acquired near shore where LIDAR may 
reflect from the shallow channel substrate. Such points, if found, were excluded from consideration.

The resulting LIDAR data for all four long-term monitoring reaches are compared with their corresponding surveyed water-edge elevations in Figure 2. Both data sets were acquired in the year 2000 under the same low, steady flow rate from the dam. The regression line of these data (shown in Figure 2) is extremely close to a 1:1 correlation. A high correlation over the entire length of the four river reaches was also observed in our bare-sand LIDAR comparisons (Davis et al., 2002), but that study also found portions of river reaches to have a lower correlation and a higher RMSE than the combined data sets due to local non-parallel relations between the LIDAR and true-ground topography. In the LIDAR water data, the overall RMSE is $30 \mathrm{~cm}$ and the RMSE's of the individual reaches are $33 \mathrm{~cm}, 24 \mathrm{~cm}, 44 \mathrm{~cm}$, and $30 \mathrm{~cm}$ from north to south. Only reach RM 43-46 has a higher RMSE than the overall average, but this reach also has the smallest sample population $(n=48)$. To better understand the level of elevation differences that can be deemed significant between the airborne LIDAR data and the historical water-profile measurements, and not due to inherent GPS error or possible LIDAR water penetration, we constructed a cumulative frequency distribution of each site's data points relative to the absolute elevation differences observed between the LIDAR and ground-surveyed elevations. The distribution for each of the four study sites is shown in Figure 3. For observed elevation differences between LIDAR and historical water elevations to be deemed statistically significant, $90 \%$ of the LIDAR elevations at a given location would have to be different from the historical data. The absolute elevation difference at $90 \%$ of each study area's sample population was 50 $\mathrm{cm}, 40 \mathrm{~cm}, 70 \mathrm{~cm}$, and $40 \mathrm{~cm}$ for study area RM 0-3, RM 29-32, RM 43-46, and RM 59-63, respectively (Figure 3 ). On land, the LIDAR data showed mostly positive vertical offsets from true topography. The land vertical offsets were $+36 \mathrm{~cm},-5 \mathrm{~cm},+6 \mathrm{~cm}$, and $+55 \mathrm{~cm}$ for the four study areas (Davis et al., 2002). In the main-stem channel, the LIDAR data show a slight negative offset from true water-surface elevation (Figure 4), with most elevation differences being between $-40 \mathrm{~cm}$ and $+20 \mathrm{~cm}$. A negative bias would be expected due to some water penetration of the laser beam before it is reflected back to the LIDAR sensor. Considering the land offsets, the penetration of the LIDAR's laser into the water must have been greater than indicated by the slightly negative bias shown by the water elevation differences and, to some degree, compensated for the positive, land elevation bias of the LIDAR data. The elevation differences observed by the Water Resources scientists exceed these levels by at least a factor of two at some locations and therefore their inferences regarding changes in riffles at those locations are probably justified.

\section{Photogrammetric Elevation Accuracies Provided by Different Image Data}

In order to determine the elevation accuracies provided by different types and resolutions of stereo image data, we derived digital elevation models (DEMs) from different types and resolutions of stereo image data using a photogrammetric workstation. Three types of stereo image data were evaluated for study area RM 43: (1) 18-cm digital panchromatic data (Figure 5); (2) 10-cm digitally scanned CIR imagery (Figure 6); and (3) 16-cm (Figure 7), 8-cm (Figure 8), 6-cm (Figure 9), and 4-cm (Figure 10) digitally scanned true-color imagery. The 4-cm true-color images $(1: 4,000$-scale imagery scanned at 10 microns) were too grainy to adequately control the image correlator on the photogrammetric workstation and were therefore not used in this study. The true-color image scans used in our photogrammetric analyses were produced at the USGS. Subsequent scans by Vexcel Corporation produced a sharper 4-cm image and this is shown as Figure 10. 
Ground control panels were placed within each study area before the August image collections, and these were used to control each photogrammetric model. Photogrammetric analysis of the CIR imagery acquired in July used fixed natural features (boulders) with known $\mathrm{x}$, $\mathrm{y}$, and $\mathrm{z}$ values because control panels were not in place during the airborne CIR data collection. Ground-elevation survey data that were acquired during these image acquisitions were not provided to the photogrammetrist. The resulting DEM data from each stereo-image analysis were compared to the ground-surveyed elevation data at the locations of the ground survey points. The locations of the 744 ground-survey points used in this comparison are shown in Figure 11.

Comparisons between photogrammetric and ground-surveyed elevations are shown graphically in Figures 12-17 for the different image data. Elevation errors are reported as root-mean-square error (RMSE). All but one of the stereo-image data sets were photogrammetrically modeled at the USGS; these are shown in Figures 12-13 and 15-17. Pacific Western Technologies (PWT) provided the initial photogrammetric analysis on the true-color image data and their results are shown in Figure 14 for comparison. All of the USGS photogrammetric elevation data were found to be vertically offset below the ground-survey elevation data (as shown in Figures 12-13 and 1517) and thus two RMSE values are reported for each of these data: one RMSE on DEM data without offset adjustment and a second RMSE on DEM data that were adjusted for the observed vertical offsets. The vertical offsets for the $18-\mathrm{cm}$ panchromatic, $10-\mathrm{cm} \mathrm{CIR}$, and $6-\mathrm{cm}$ and $8-\mathrm{cm}$ true-color data were in the range of $42-64 \mathrm{~cm}$, while the $16-\mathrm{cm}$ true-color data had a $99 \mathrm{~cm}$ vertical offset.

We found that the 18-cm panchromatic stereo image data (Figure 12) produced the highest RMSE (53 cm offset adjusted), which is almost a factor of two higher than the $20-\mathrm{cm}$ vertical accuracy that is acceptable for physical resource monitoring. This higher RMSE was anticipated because of the lack of geometric calibration for digital CCD cameras at this time. Even though the panchromatic data were acquired with a $4096 \times 4096$ CCD array, photogrammetrists believe CCD arrays at least the size of 10,000 x 10,000 are needed in order to approach the geometric accuracy provided by cartographic cameras and required by photogrammetry. The 10-cm CIR image data produced accuracies (offset-adjusted RMSE of 31 $\mathrm{cm}$; Figure 13) close to acceptable levels and close to the accuracy obtained by PWT (Figure 14). This is remarkable considering the fact that only natural features with known $\mathrm{x}, \mathrm{y}$, and $\mathrm{z}$ values were used to control the photogrammetric model (because panels were not in place during CIR data collection). Offset-adjusted RMSE values for the photogrammetric data derived from the three different scan resolutions for the true-color imagery (Figure 15-17) decreased from $43 \mathrm{~cm}$ to $39 \mathrm{~cm}$ to $35 \mathrm{~cm}$ in the order of increasingly higher scan resolutions, with results from the highest resolution data approaching the $28 \mathrm{~cm}$ accuracy provided by the PWT analysis, but not as close as the CIR data. The locations of high elevation errors in all of these different stereo-image analyses are similar and are shown on Figures 18-23 and are discussed in the following paragraphs.

First, most of the largest elevation errors $(\geq 1 \mathrm{~m})$ in all of these photogrammetric analyses (even in the PWT analysis) occur along the edge of the tall, dense tamarisk groves that border the central sand bar (the red dots in Figures 18-23). The PWT analysis and the CIR analysis produced the fewest large errors at these locations (Figures 19 and 23), which accounts for their higher vertical accuracy relative to the other analyses. The occurrence of high elevation errors along canopy borders is a relatively common problem in photogrammetry and requires special analytical methods (Gong et al., 2002). The panchromatic elevation data also had a significant number of large elevation errors within the isolated grove of sparse tamarisk trees that protrudes onto the western side of the central sand bar (Figure 18). These additional errors produced the higher RMSE value for the panchromatic DEM data relative to the other image data. Even though panchromatic data provide sharper imagery, it is difficult to discriminate shadows from vegetation in panchromatic data because both are dark in such imagery. 
Second, the photogrammetric results from the panchromatic imagery show more elevation errors along the shoreline (Figure 18) than do the other image analyses. These shoreline errors are attributed to the ambiguity in detecting the water's edge in broadband panchromatic images relative to that using CIR or natural-color imagery.

Third, all of the photogrammetric analyses produced a concentration of errors at the 0.5 $1.0 \mathrm{~m}$ level on the non-vegetated sand bar in the southeast corner of the study area (Figures 1823). There are two possible reasons for these elevation discrepancies. The sand bar may have too little texture or too subtle topography for the photogrammetric workstation to "see" relief. Alternatively, the ground-survey data may be incorrect, but it would be difficult for the survey crew to miss a relief change of that magnitude in plain sight.

Fourth, in terms of unadjusted RMSE, the 18-cm panchromatic and the 16-cm scanned true-color image data provide much lower vertical accuracies (RMSE values a factor of two higher) than the higher resolution 10-cm CIR and 8-cm and 6-cm true-color image data.

Photogrammetry appears to set one limit on the spatial resolution required for physical resource monitoring: stereo image data need to be acquired such that digitally acquired or scanned image data retain at least a $10-\mathrm{cm}$ ground resolution. Considering just the USGS results for internal consistency, the CIR imagery (Figure 19) appears to produce fewer large ( $\geq 1 \mathrm{~m}$ ) errors within vegetated terrain than does the true-color imagery (Figures 20-22). We did not acquire panchromatic film within the last few years, so we could not evaluate this type of data. However, panchromatic film probably produces much better photogrammetric results than those obtained from the digital panchromatic data because photogrammetrists routinely use panchromatic film and obtain required map accuracies with these data. Even if reliable photogrammetric data could be derived from a digital camera system, the cost for acquiring digital image resolutions near $8-10 \mathrm{~cm}$ is so high (because a helicopter is needed to collect the data) that digital cameras will not satisfy GCMRC topographic monitoring requirements. Although our photogrammetry evaluations did not strongly indicate a preference for a particular type of image data, the image requirements for corridor-wide inventory of sand bars and debris flows may do so.

\section{Sediment Deposit Characteristics Provided by Different Image Data}

There are two characteristics of sand bars and debris flows that human perception uses to distinguish these two geomorphic units: color or brightness and roughness or texture (Haralick et al., 1973). Study area RM 43 has large areal exposures of both geomorphic units (Figure 24). We examined different image data that were collected over this reach to determine (1) the ability of different types of image data to segregate vegetation from geologic materials, which is a critical step in quantifying texture of geologic surfaces; (2) the degree of textural separation between sand-bar and debris-flow surfaces provided by each type image data, which affects mapping accuracy; and (3) the mapping capability for sand bars and debris flows provided by the color and textural information from true-color and CIR image data. These evaluations were designed to determine the best image data to collect to provide these capabilities and were not designed to determine the best method or absolute accuracy for such mapping.

In order to accurately represent the texture of just the geologic surfaces, the vegetation on these surfaces must be removed by preparing vegetation masks. Panchromatic data (Figure 5) gather reflected light from the blue through the near-infrared wavelength region. Vegetation has very little reflectance in blue and red wavelength regions, and little reflectance even in the green 
wavelength region. Thus, the integrated panchromatic reflectance from vegetation is very low causing vegetation to appear dark in panchromatic imagery. Shadows cast by large rock fragments are also dark and, therefore, segregation of vegetation on panchromatic imagery will be either (1) incomplete so as not to remove too many rock shadows or dark rock fragments, or (2) counterproductive in that much or all of the rock shadows and dark geologic materials are removed in trying to eliminate most vegetation. The pigments in vegetation absorb most light at red wavelengths, some light at green wavelengths, and essentially no light at near-infrared wavelengths. Geologic materials reflect most light between blue to near-infrared wavelengths, with reflectance generally increasing from blue to near-infrared wavelengths due to iron oxidation. Thus, CIR imagery, which records green, red, and near-infrared reflectance information from a surface, shows vegetation as brilliant shades of red, which are distinctly different from the CIR colors of geologic materials (Figure 6). For this reason, many vegetation indices use ratios of near-infrared reflectance to red reflectance, such as the normalized difference vegetation index (NDVI), to very effectively separate vegetation from geologic materials. Truecolor imagery records energy reflected in the blue, green, and red wavelength regions. Most geologic and vegetation surfaces reflect very little blue-wavelength energy, but both surfaces reflect green-wavelength energy with vegetation reflecting more green-wavelength energy. Thus, true-color images display vegetation as shades of green (Figure 7). At first glance, truecolor data appear to easily distinguish vegetation and geology by the vegetation's brighter shades of green. Because vegetation is greener and much less red than geologic materials, we tried a green/red ratio to separate vegetation from geologic materials, but this was not nearly as effective as the CIR NDVI ratio. Similar results have been obtained in previous studies (e.g., Chavez, 1992). Other ratios, as well as just the green image, were even less effective. Thus, we had to compromise by removing as much vegetation as possible using the green/red ratio until the process began to remove significant shadows and alluvium.

We removed vegetation from the panchromatic and color image data using their respective vegetation masks produced in the previous process. We then applied a series of variance filters to the remaining "bare-ground" picture elements in the image data. The spatial dimensions of the filter were increased until there was either clear separation or clear indication of no separation in the majority of the variance values for the sand-bar and debris-flow surfaces. The results from the variance filters are shown as frequency distributions of sand-bar and debrisflow variance values for filter dimensions that show (or never show) the transition toward textural separation (Figures 25-28).

The panchromatic image data did not provide good textural separation of the two surfaces. Improvements in textural separation cease near a variance filter dimension of $69 \times 69$, which equates to an areal dimension of $12.5 \mathrm{~m} \mathrm{x} 12.5 \mathrm{~m}$ (Figure 25). This is attributed to the inability of broad-wavelength image data to adequately separate and remove vegetation from geologic information (i.e., sunlit rocks and their shadows); the remaining vegetation adds texture to the geologic surfaces. On the other hand, the CIR image data provide a very good textural separation between the two surfaces (Figure 26). This is attributed to the clear distinction between vegetation and geologic materials provided by the NVDI ratio, which effectively removed vegetation without removing much of the rock fragments or the shadows they cast. We examined the variance provided by different CIR bands and found all three bands to provide nearly the same degree of textural separation (Figure 27). The true-color image data did not produce the clear separation in surface texture that is shown by the CIR data (Figure 28) because both vegetation and geologic materials produce some green-wavelength reflectance. The truecolor data did provide better textural separation than the panchromatic image data. However, for corridor-wide computer mapping of sand bars and debris flows, CIR imagery provides a superior textural database. 
Even though true-color imagery does not provide superior textural information, it may provide better color distinction than CIR imagery between sand-bar and debris-flow surfaces, which ultimately might produce a better mapping tool for these surfaces. In order to evaluate the relative merits of the color and combined color and texture data provided by true-color and CIR image data for mapping sand bars and debris flows, we performed a series of supervised, minimum-distance classifiers on these data. We first performed a supervised classifier on the color-band data provided by the true-color (Figure 29a) and the CIR (Figure 30a) image data. The classification using the CIR color data (Figure 30c) produced a much more accurate map of these sediment deposits than did the true-color classification (Figure 29c); the true-color classification appears to have missed even the most obvious sand-bar deposits along the shoreline. When texture was also considered in the supervised classification, the results from both CIR (Figure 30d) and true-color (Figure 29d) analyses improved over the classification results obtained using only their color information. The map results from the true color data (Figure 29d) now approach those produced by the CIR data (Figure 30d), but the CIR image data still produce a more accurate representation of the two sediment surfaces than do the true-color image data. In fact, the classification results using just the CIR color information (Figure 30c) are very similar to the results obtained using both CIR color and texture (Figure 30d). Thus, CIR imagery provides more relevant surface composition information than does true-color imagery. All of these image analyses indicate that CIR image data should be preferentially acquired for GCMRC physical resource monitoring. As far as computer mapping of these sediment deposits, more research needs to be performed to devise an algorithm that can uniquely identify sand bars and debris flows to a much better degree than shown in this evaluation.

\section{Conclusions}

Our evaluations of LIDAR data for the CRE main-stem show that near-infrared LIDAR does in fact provide average water-surface elevations. However, as on land, LIDAR has inherent errors, and changes at any particular location on the main stem from previous measurements need to be represented by the majority of the LIDAR data at a particular location (preferably $90 \%$ of the data) and the change must exceed the 50-cm RMSE that we found in these data in order to be deemed a true change in water-surface elevation.

Our photogrammetric analyses of airborne imagery show that CIR imagery produce fewer large elevation errors within vegetation, but not significantly better in overall accuracy to that produced using the true-color imagery. The digital panchromatic data were found to be unacceptable. Our results also show that an image resolution of $\leq 10 \mathrm{~cm}$ is required to achieve the vertical accuracy $(\leq 20 \mathrm{~cm})$ required for GCMRC monitoring of sand bars and that photogrammetric analysis needs to be carefully performed near vegetation borders in order to achieve that accuracy. In terms of corridor-wide mapping of sediment deposits with automated computer techniques, we found that CIR image data are far superior to panchromatic and truecolor image data, which was also the findings of our evaluations of these data for the biologic resource program. Thus, the overall recommendation for GCMRC physical resource monitoring is to obtain CIR image data and, when photogrammetry is required, these data need to be acquired at the resolutions stated above.

\section{References Cited}

Chavez, P. S., 1992, Comparison of spatial variability in visible and near-infrared spectral images. Photogrammetric Engineering and Remote Sensing 58, 957-964. 
Davis, P., Manone, M., Mietz, S., Kohl, K., Rosiek, M., Hazel, J., Kaplinski, M., and Gonzales, M., 2002, Evaluation of LIDAR and photogrammetry for monitoring volume changes in riparian resources within the Grand Canyon, Arizona. Pecora 15/Land Satellite Information IV Conference, Nov. 10-14, Denver, CO, 6 p.

Gong, P., Mei, X., Biging, G. S., and Zhang, Z., 2002, Improvement of an oak canopy model extracted from digital photogrammetry. Photogrammetric Engineering and Remote Sensing 63, 919-924.

Haralick, R. M., Shammugam, K., and Dinstein, I., 1973, Textural features for image classification. IEEE Transactions on System, Man, and Cybernetics SMC-3, 610-621.

Irish, J. L., and Lillycrop, W. J., 1999, Scanning laser mapping of the coastal zone: the SHOALS system. ISPRS Journal of Photogrammetry and Remote Sensing 54, 123-129. 


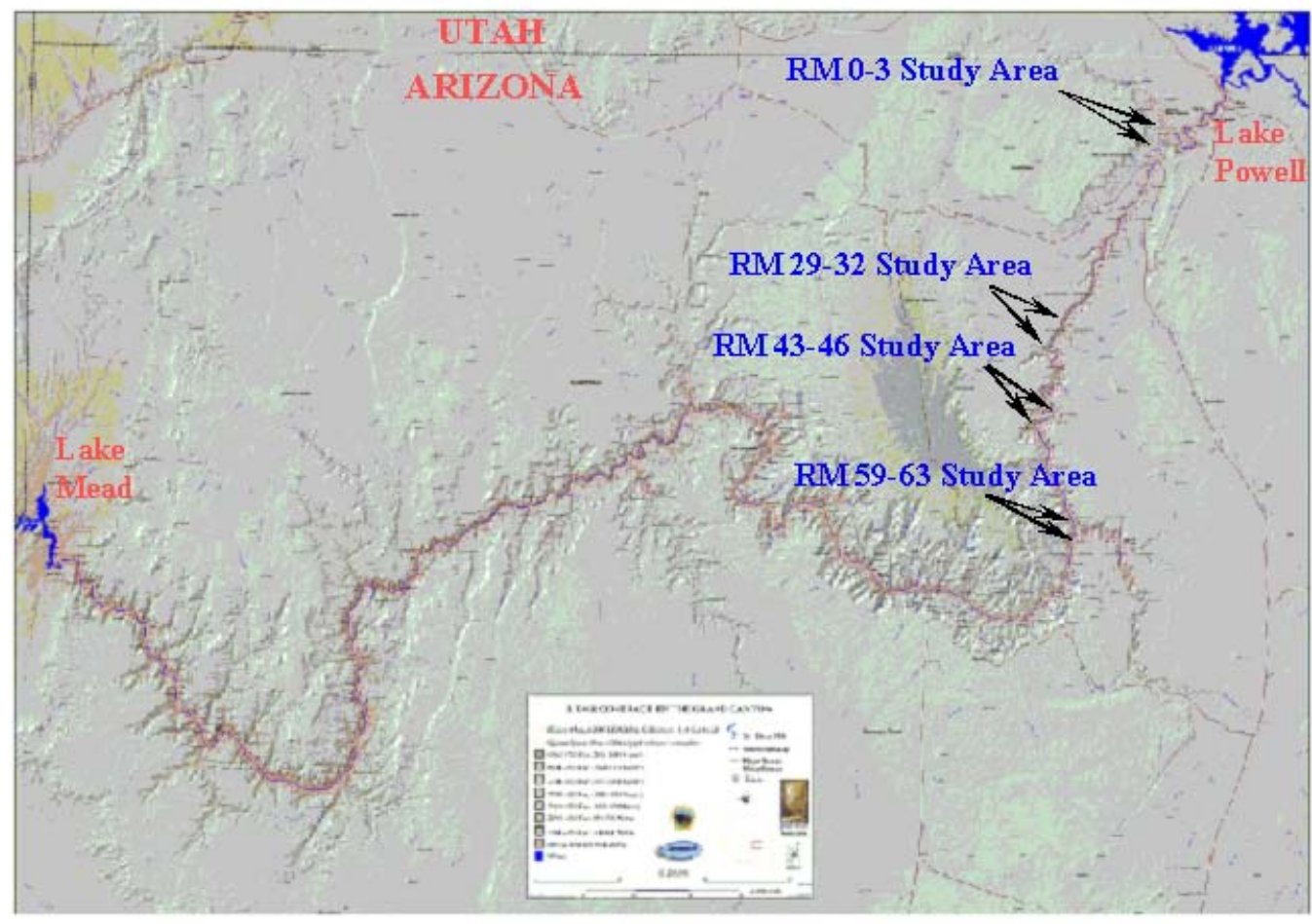

Figure 1. Index map of the Colorado River ecosystem in Arizona showing locations of the longterm monitoring sites used in this study to evaluate LDAR data and image data for physical resource monitoring requirements 


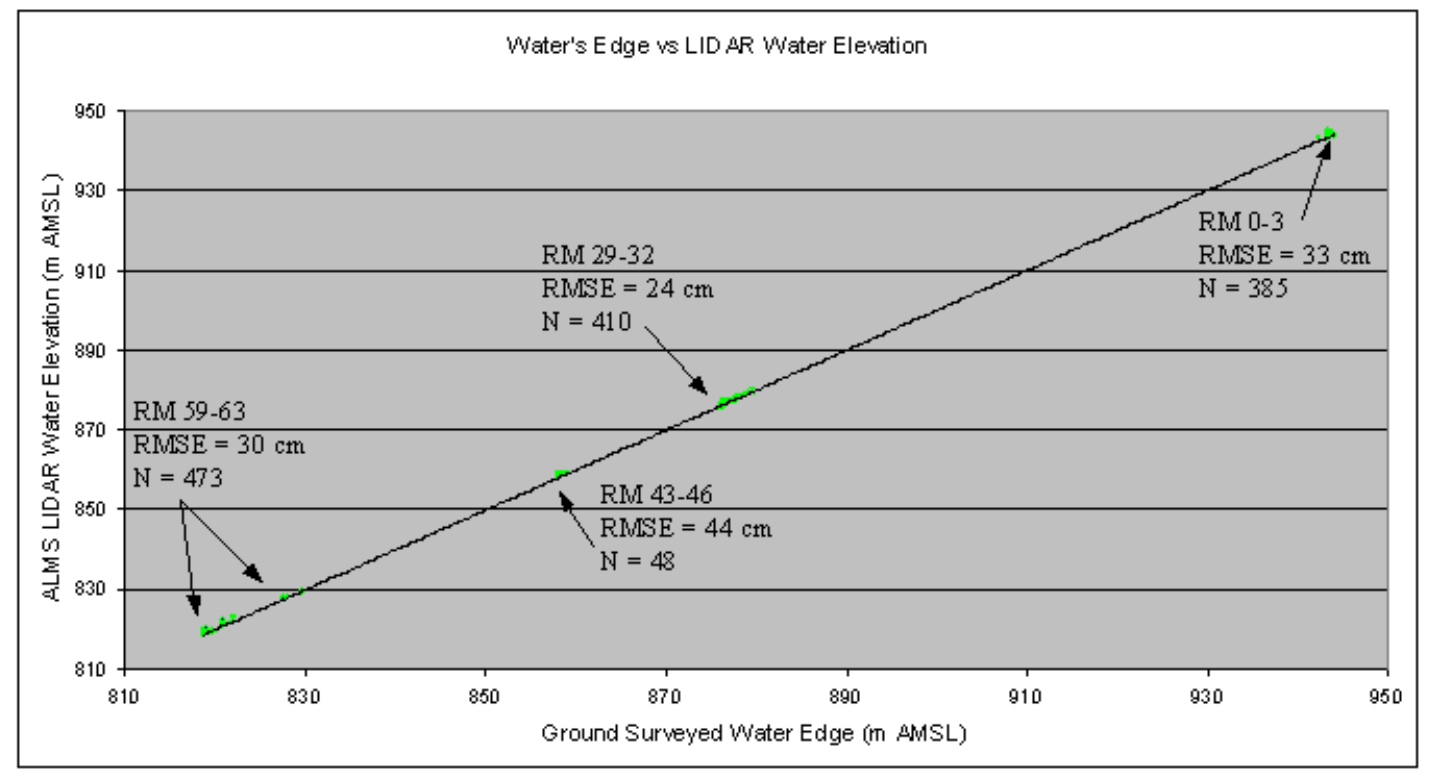

Figure 2. Comparison between $L I D A R$ main-stem and ground-surveyed water-edge el evations for the four long-term monitoring sites. Line represents least-squares regression of all data and is extremely close to a 1:1 correlation. Errors and number of samples indicated for each site.

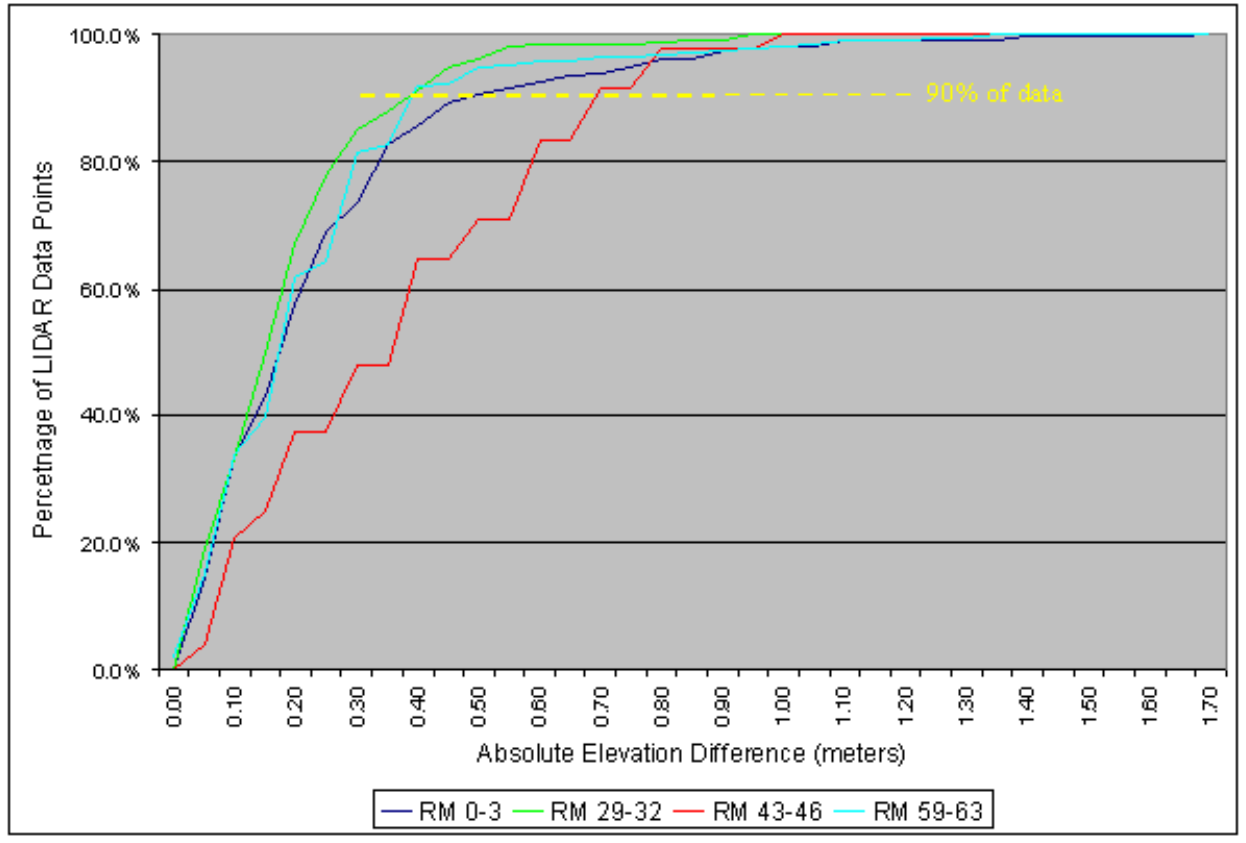

Figure 3. Cumulative sample population of LDAR main-stem data relative to their absolute elevation differences from ground-surveyed water-edge elevations at the four long-term monitoring sites. 


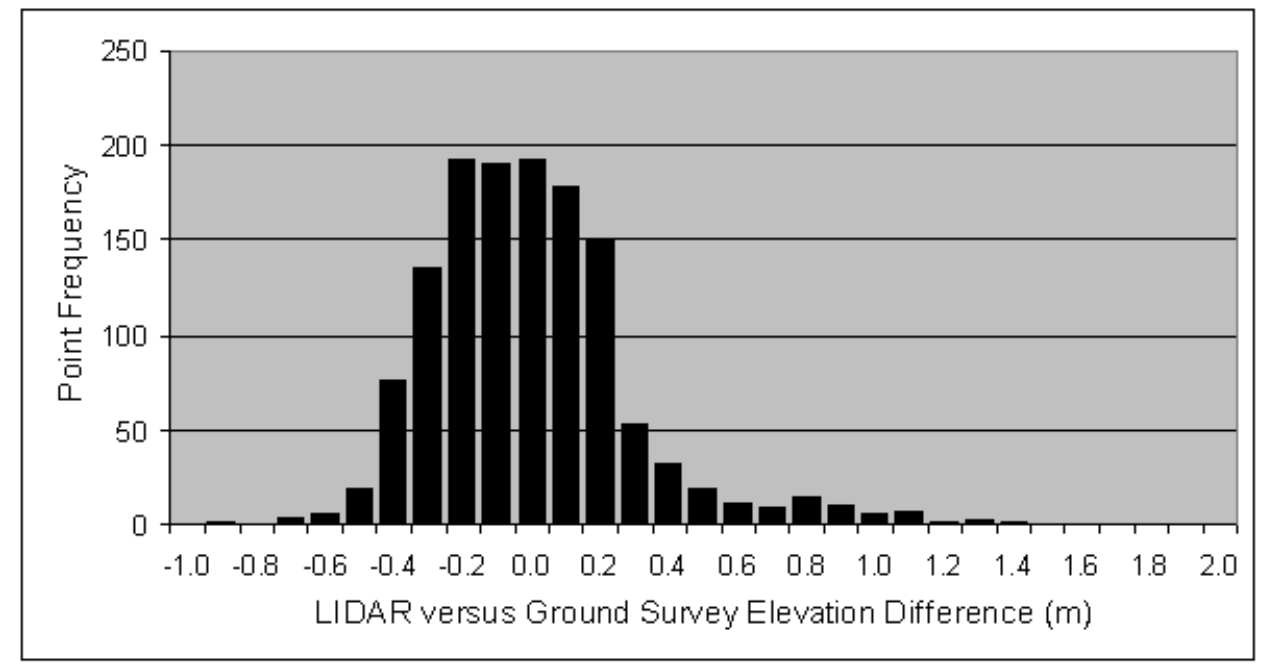

Figure 4. Point frequency distribution of elevation differences between LIDAR main-stem data and ground-survey water-edge data. 


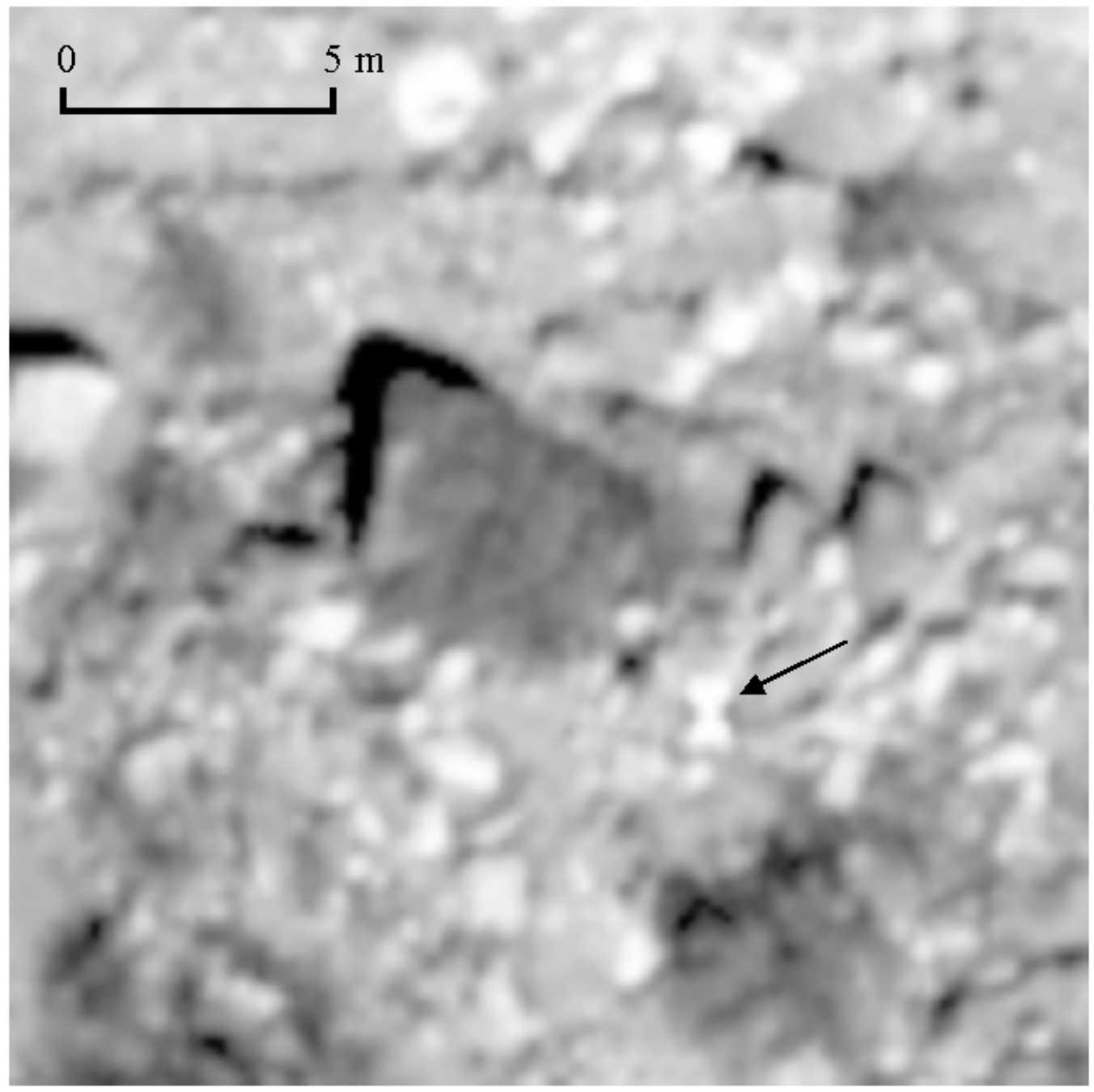

Figure 5. 18-cm digital panchromatic image of debris flow surface at RM 43 study area. Vegetation is dark and difficult to distinguish from shadows cast by large rock fragments and even some of the rock fragments themselves. Differences between geologic materials are also difficult to distinguish. This image is a portion of an orthorectified mosaic and has therefore been resampled to some degree. Four-foot control panel near image center (indicated by arrow) has an hourgl ass shape. 


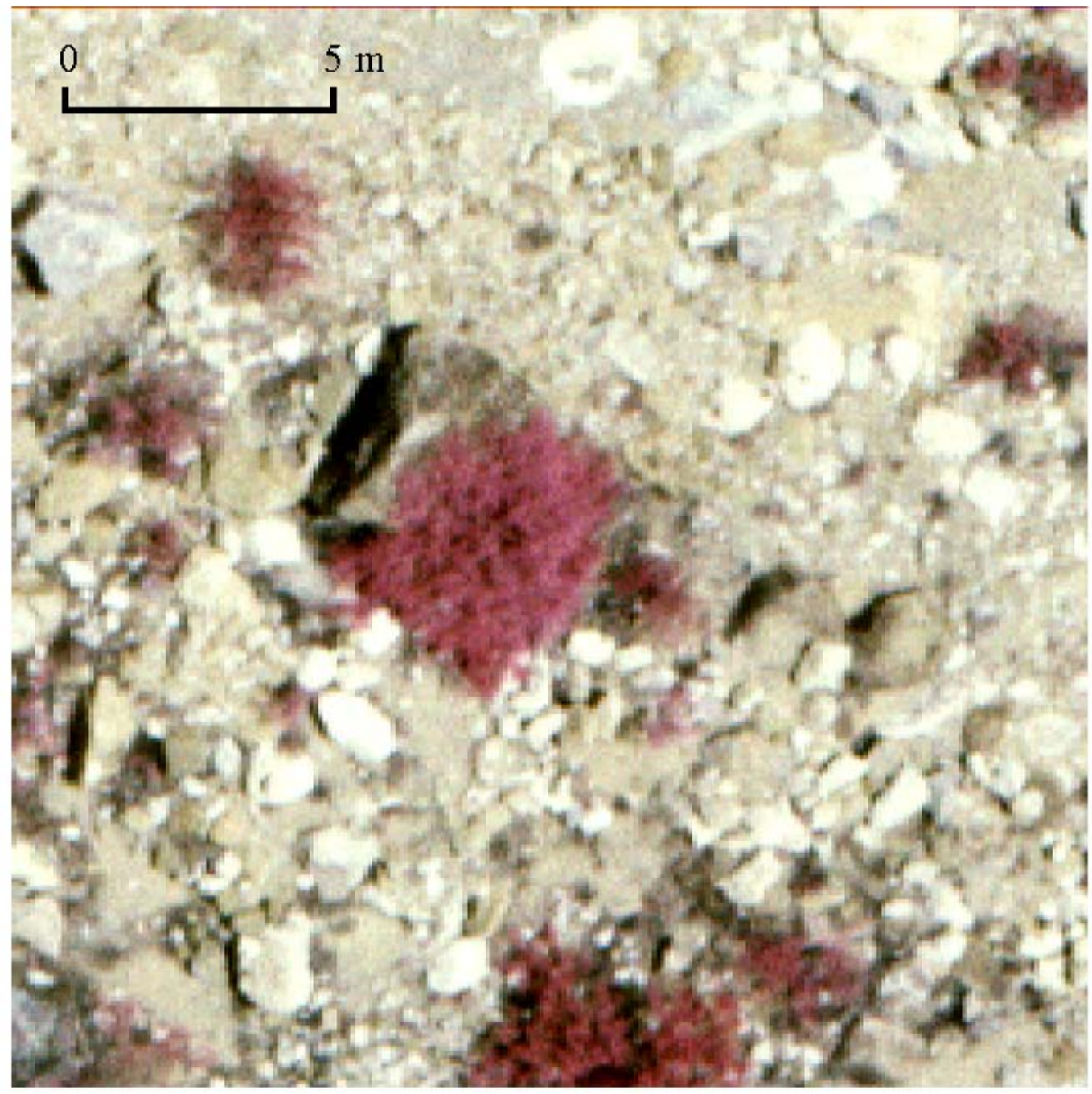

Figure 6. 10 -cm CRR image ( 21 micron scan of 1:4,800-scale film) of debris flow surface at RM 43 study area. Vegetation has very distinct shades of red. Some geologic materials tend to be washed out or saturated white. Image represents the original orientation (no geometric resampling) and scanned col or bal ance. Control panel shown in other image data (Figures 5 and 7-10) not present on surface during image acquisition. 


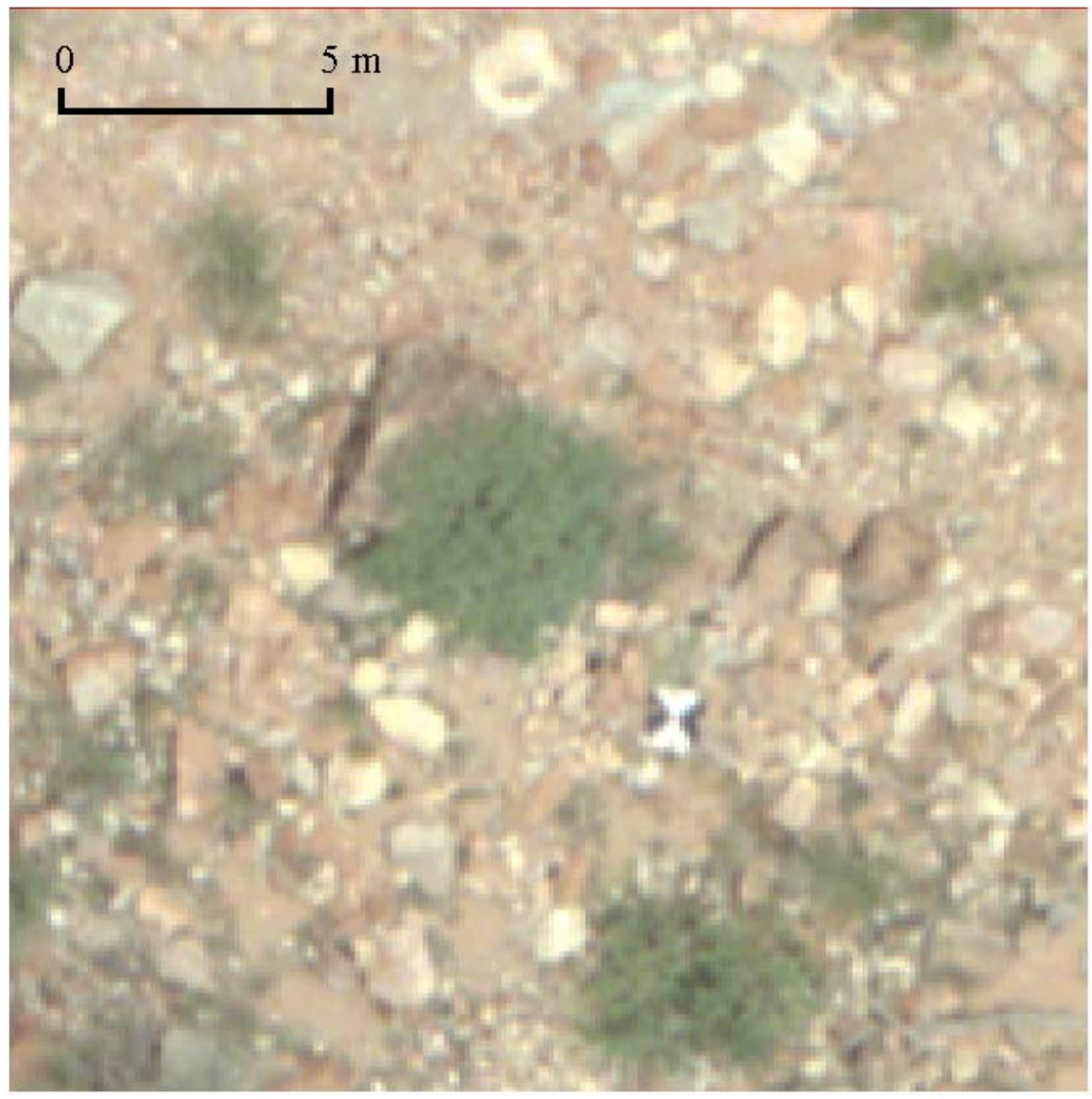

Figure 7. 16-cm true-color image ( 40 micron scan of 1:4,000-scale film) of debris flow surface at RM 43 study area. Vegetation is green. Geologic materials have their natural colors with little to no saturation. Image represents the original orientation (no geometric resampling) and scanned color balance. Four-foot control panel near image center has an hourglass shape. 


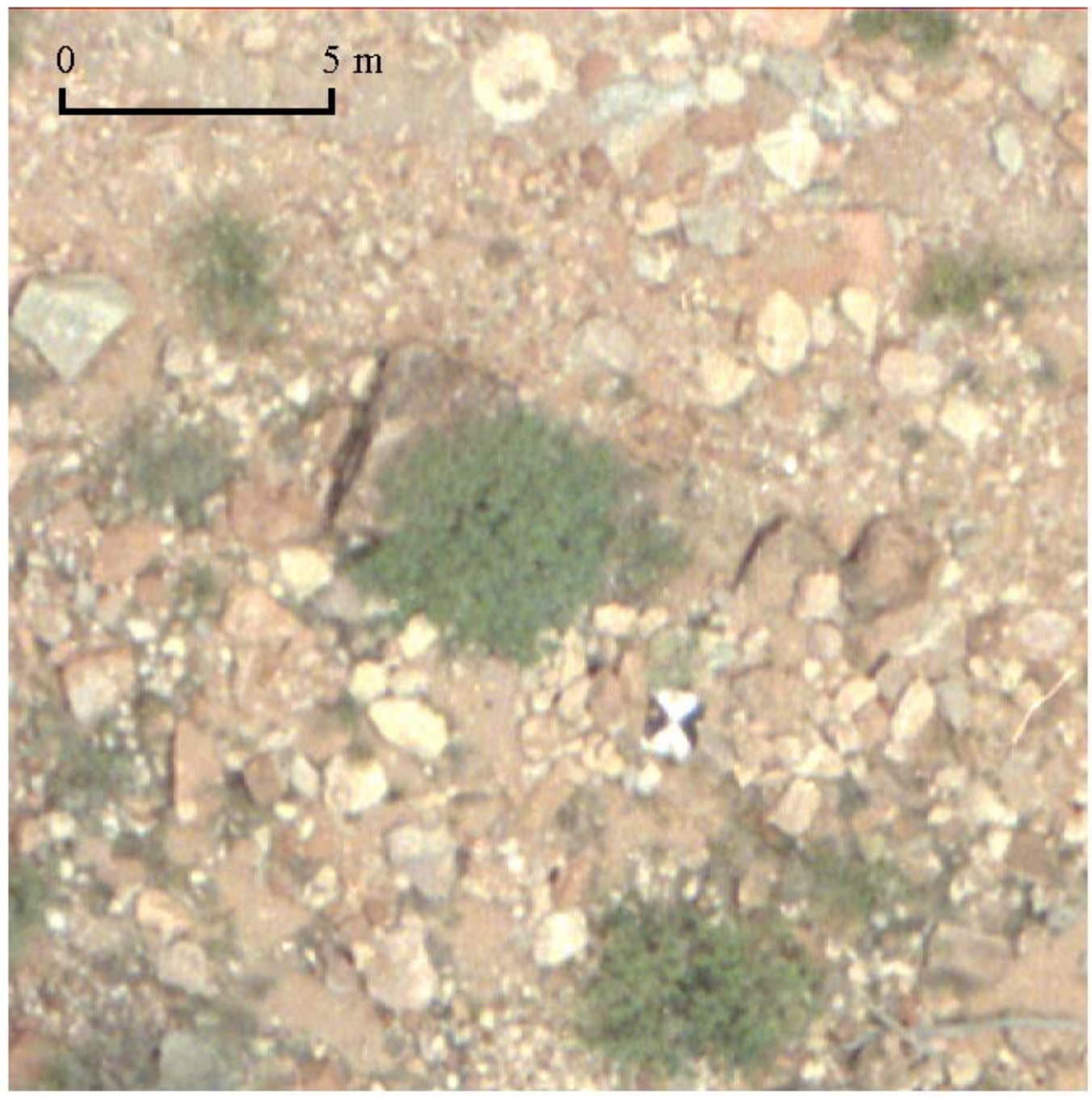

Figure 8. 8-cm true-color image ( 20 micron scan of 1:4,000-scale film) of debris flow surface at RM 43 study area. Vegetation is green. Geologic materials have their natural colors with little to no saturation. Image represents the original orientation (no geometric resampling) and scanned color balance. Four-foot control panel near image center has an hourglass shape. 


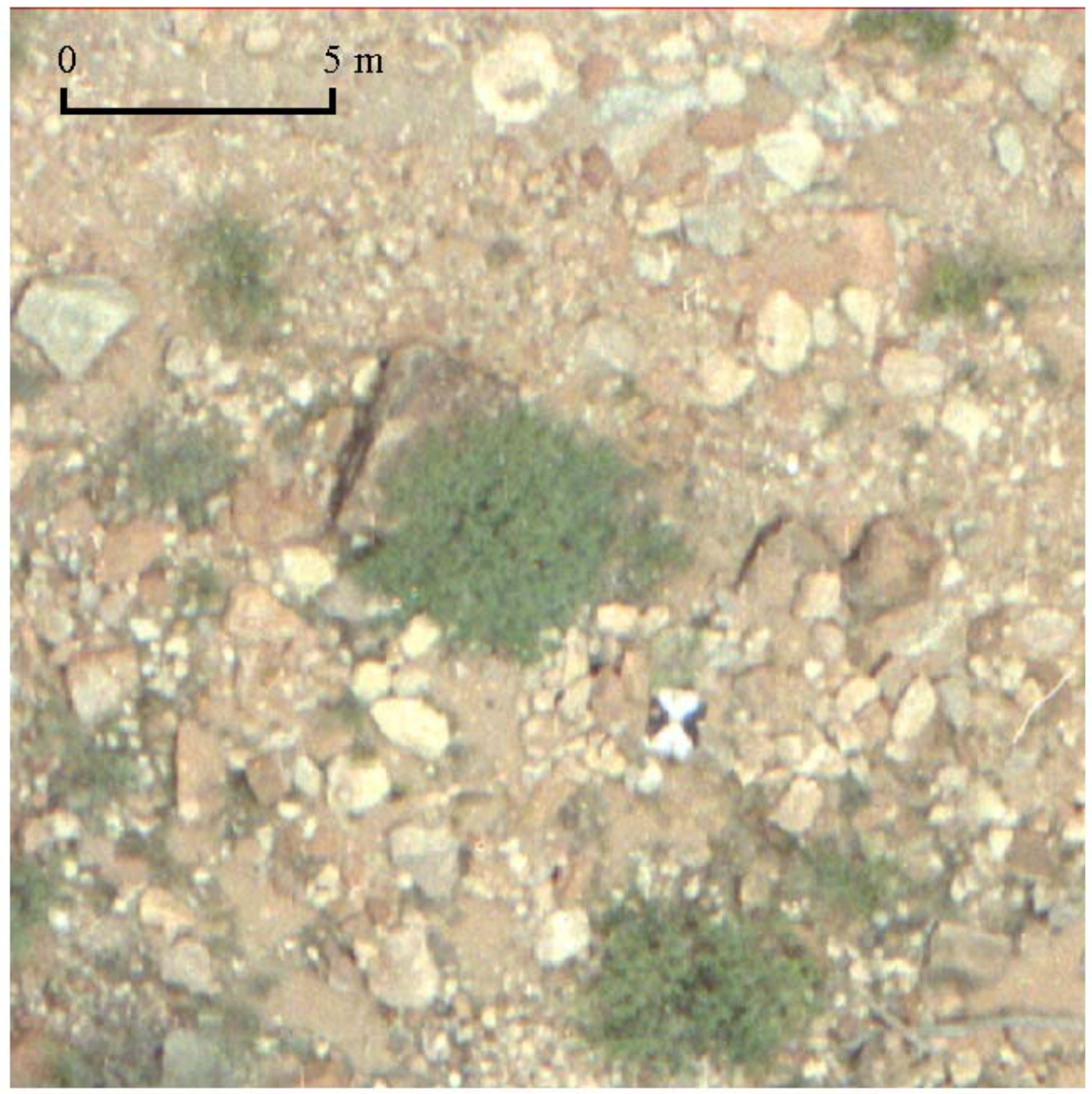

Figure 9. 6-cm true-color image ( 15 micron scan of 1:4,000-scale film) of debris flow surface at RM 43 study area. Vegetation is green. Geologic materials have their natural colors with little to no saturation. Image represents the original orientation (no geometric resampling) and scanned color balance. Scan resolution is near the limit of the film resolution. Four-foot control panel near image center has an hourglass shape. 


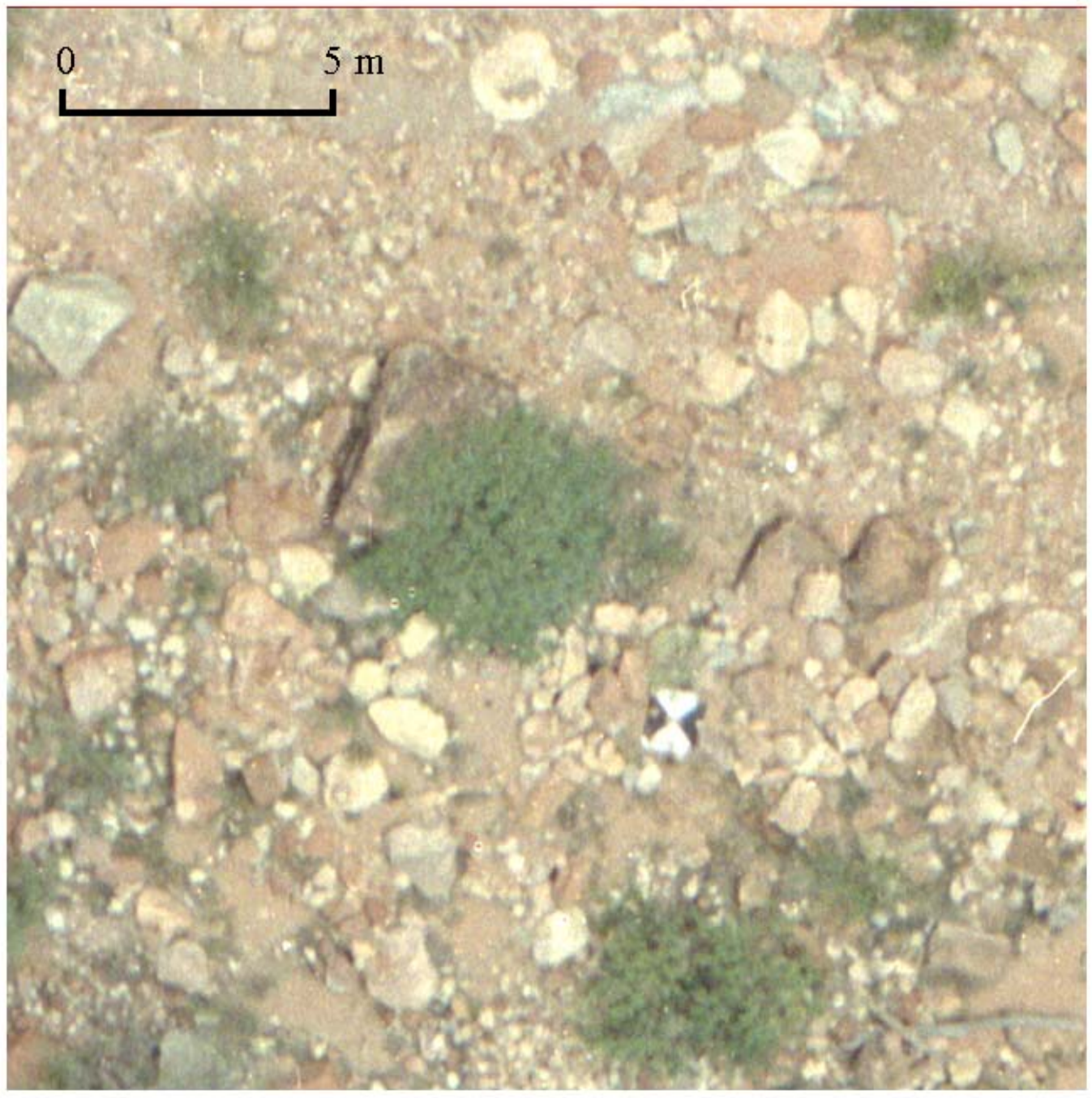

Figure 10. 4-cm true-color image (10 micron scan of 1:4,000-scale film) of debris flow surface at RM 43 study area. Vegetation is green. Geologic materials have their natural colors with little to no saturation. Im age represents the original orientation (no geometric resampling) and scanned color balance. Scan resolution is near the limit of the film resolution. Four-foot control panel near image center has an hourglass shape. 


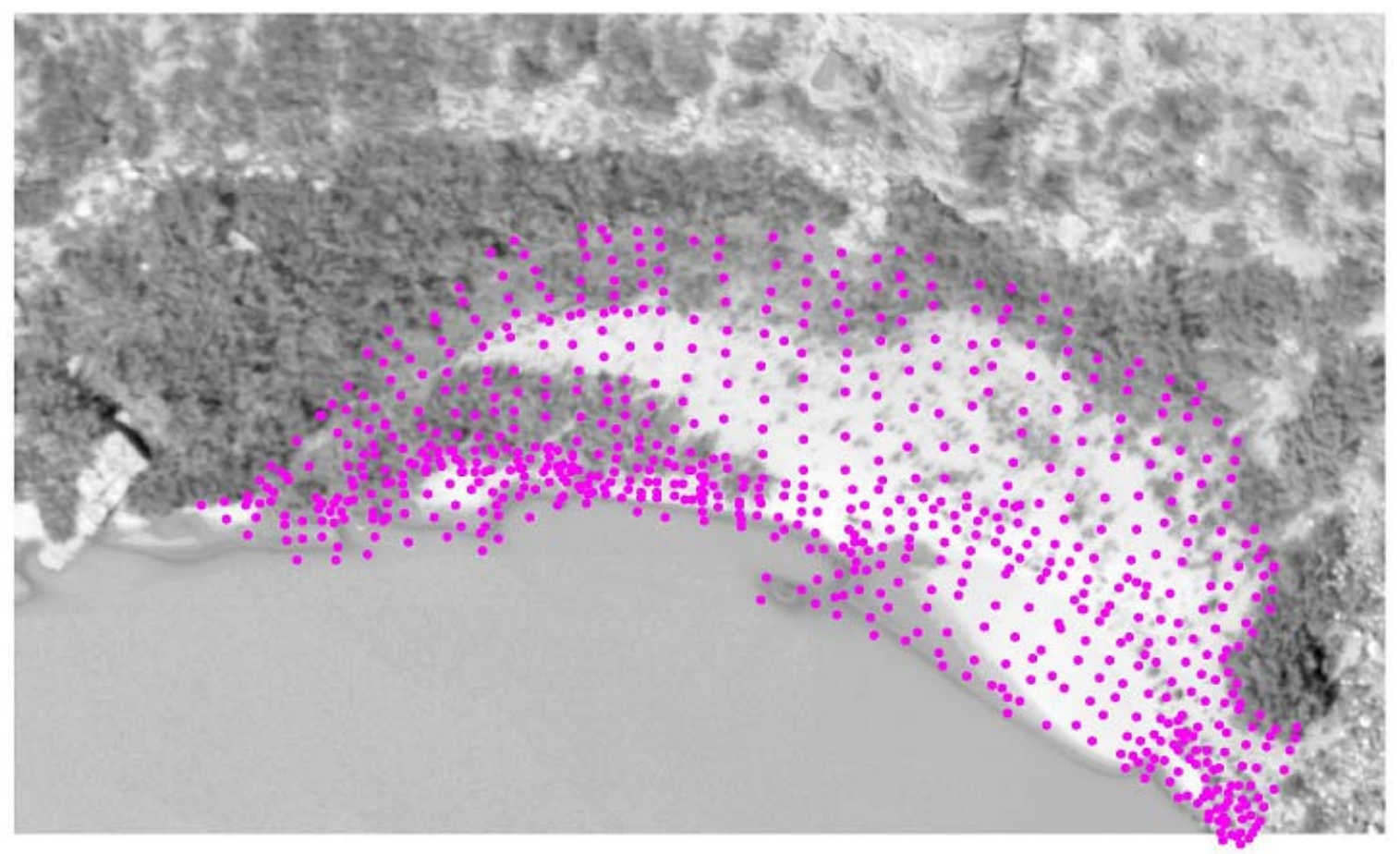

Figure 11. Panchromatic image of study area RM 43 in the CRE showing the distribution of ground-survey elevations used to determine the accuracy of photogrammetric analyses on different types and resolutions of stereo imagery. 


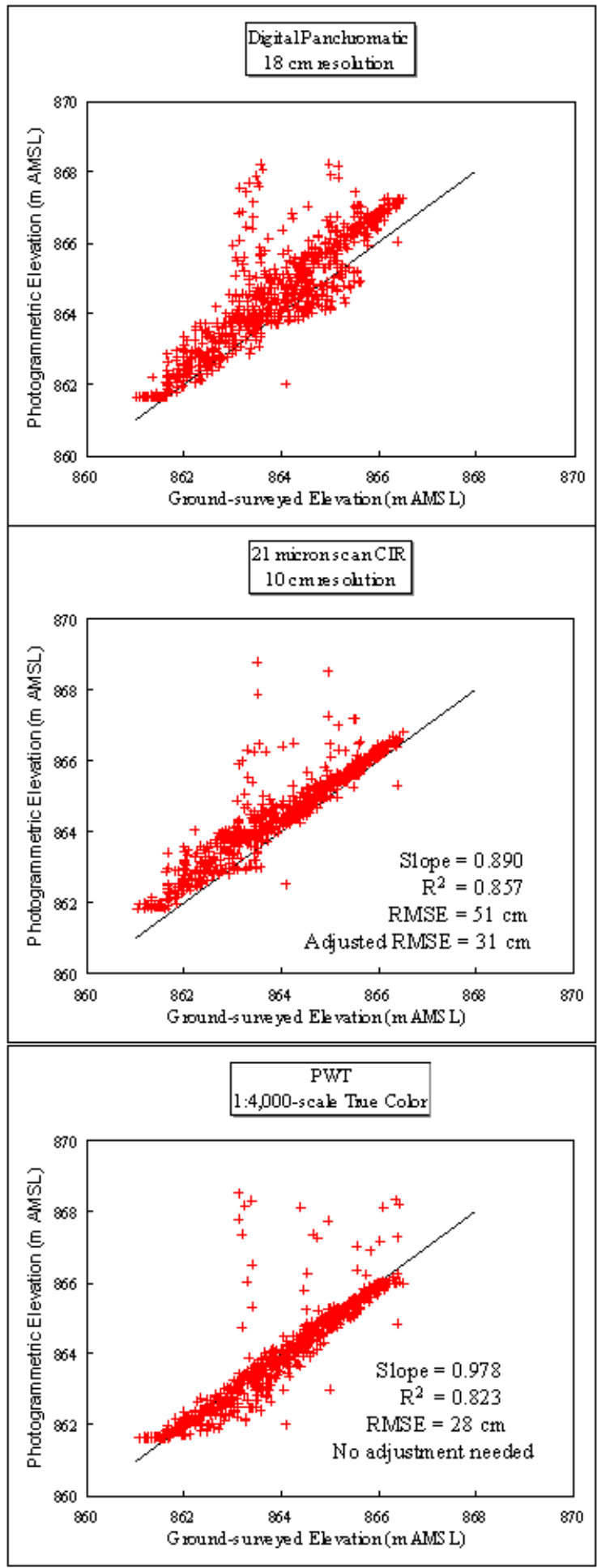

Figure 12. Comparison of photogrammetric ground el evations derived from $18-\mathrm{cm}$ digital panchromatic image data with surveyed ground elevations. Line represents a 1:1 relation. Adjusted RMSE values derived from photogrammetric elevations have been adjusted downward for an observed average vertical offset from groundsurvey elevation data.

Figure 13. Comparison of photogrammetric ground el evations derived from $10-\mathrm{cm}$ scanned CIR film image data with surveyed ground elevations. Line represents a 1:1 relation. Adjusted RMSE values derived from photogrammetric elevations have been adjusted downward for an observed average vertical offset from groundsurvey elevation data.

Figure 14. Comparison of photogrammetric ground elevations derived by Pacific Western Technologies (PWT) using 1:4,000-scale true-color film with surveyed ground elevations. Line represents a 1:1 relation. 


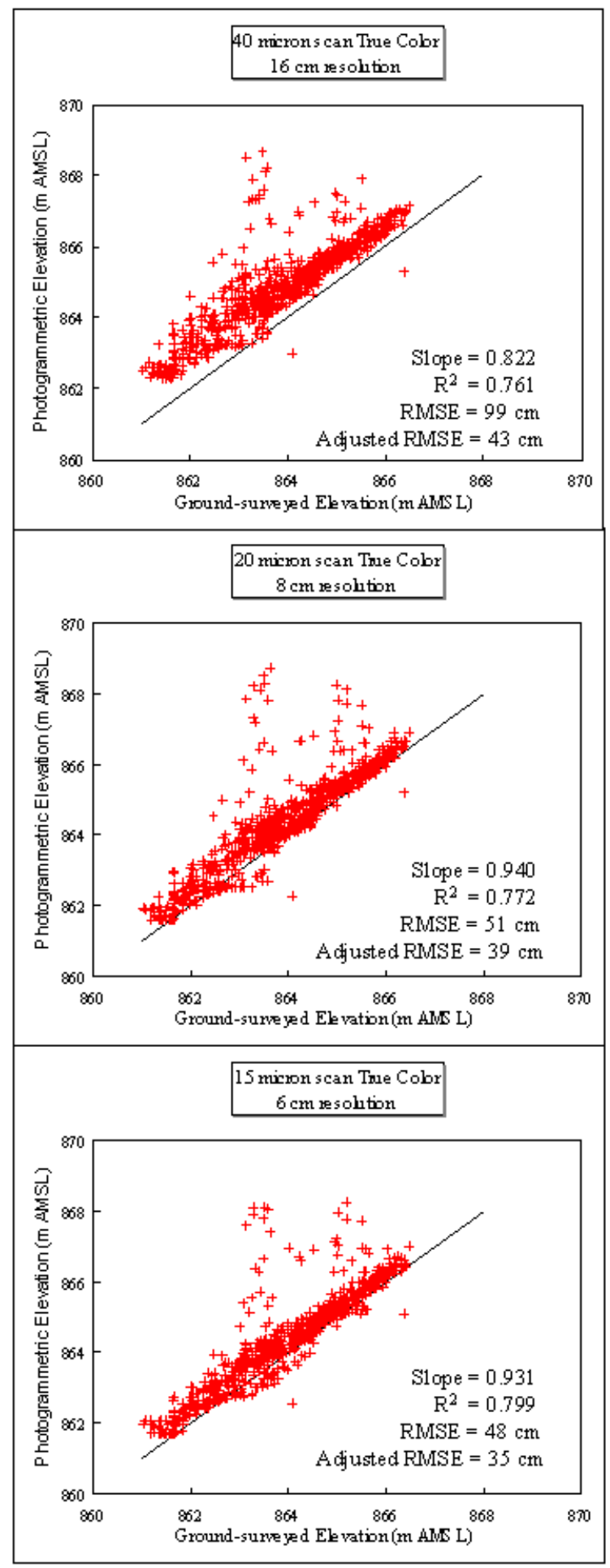

Figure 15. Comparison of photogrammetric ground el evations derived from $16-\mathrm{cm}$ scanned true-color film image data with surveyed ground elevations. Line represents a 1:1 relation. Adjusted RMSE values derived from photogrammetric elevations have been adjusted downward for an observed average vertical offset from groundsurvey elevation data.

Figure 16. Comparison of photogrammetric ground el evations derived from $8-\mathrm{cm}$ scanned true-color film image data with surveyed ground elevations. Line represents a 1:1 relation. Adjusted RMSE values derived from photogrammetric elevations have been adjusted downward for an observed average vertical offset from groundsurvey elevation data.

Figure 17. Comparison of photogrammetric ground el evations derived from $6-\mathrm{cm}$ scanned true-color film image data with surveyed ground elevations. Line represents a 1:1 relation. Adjusted RMSE values derived from photogrammetric elevations have been adjusted downward for an observed average vertical offset from groundsurvey elevation data. 


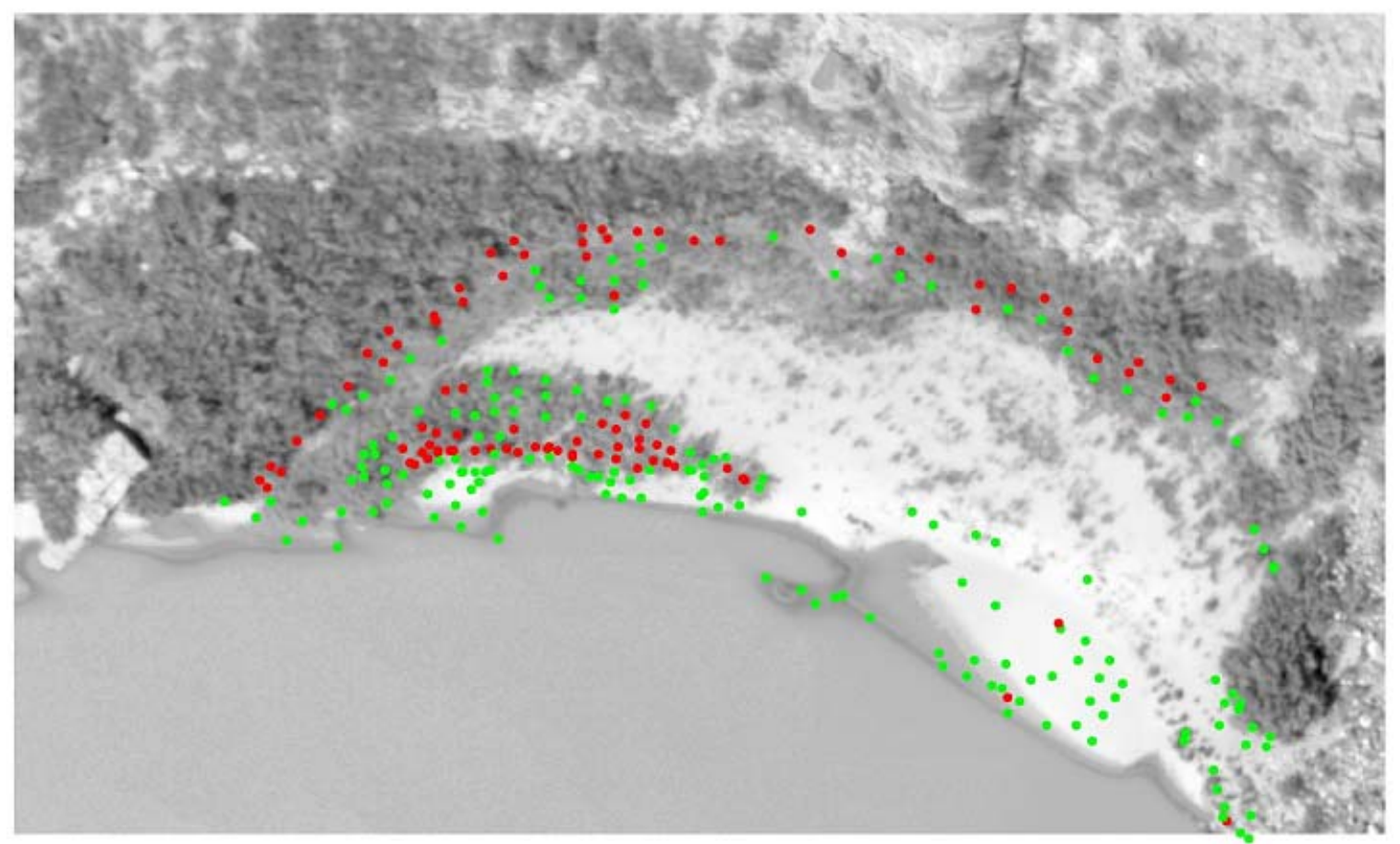

Figure 18. Panchromatic image of RM 43 study area showing locations of el evation errors equal to or greater than $1 \mathrm{~m}$ (red) and errors between 0.5 and $0.99 \mathrm{~m}$ (green) derived from photogrammetric analysis of the $18-\mathrm{cm}$ digital panchromatic image data. 


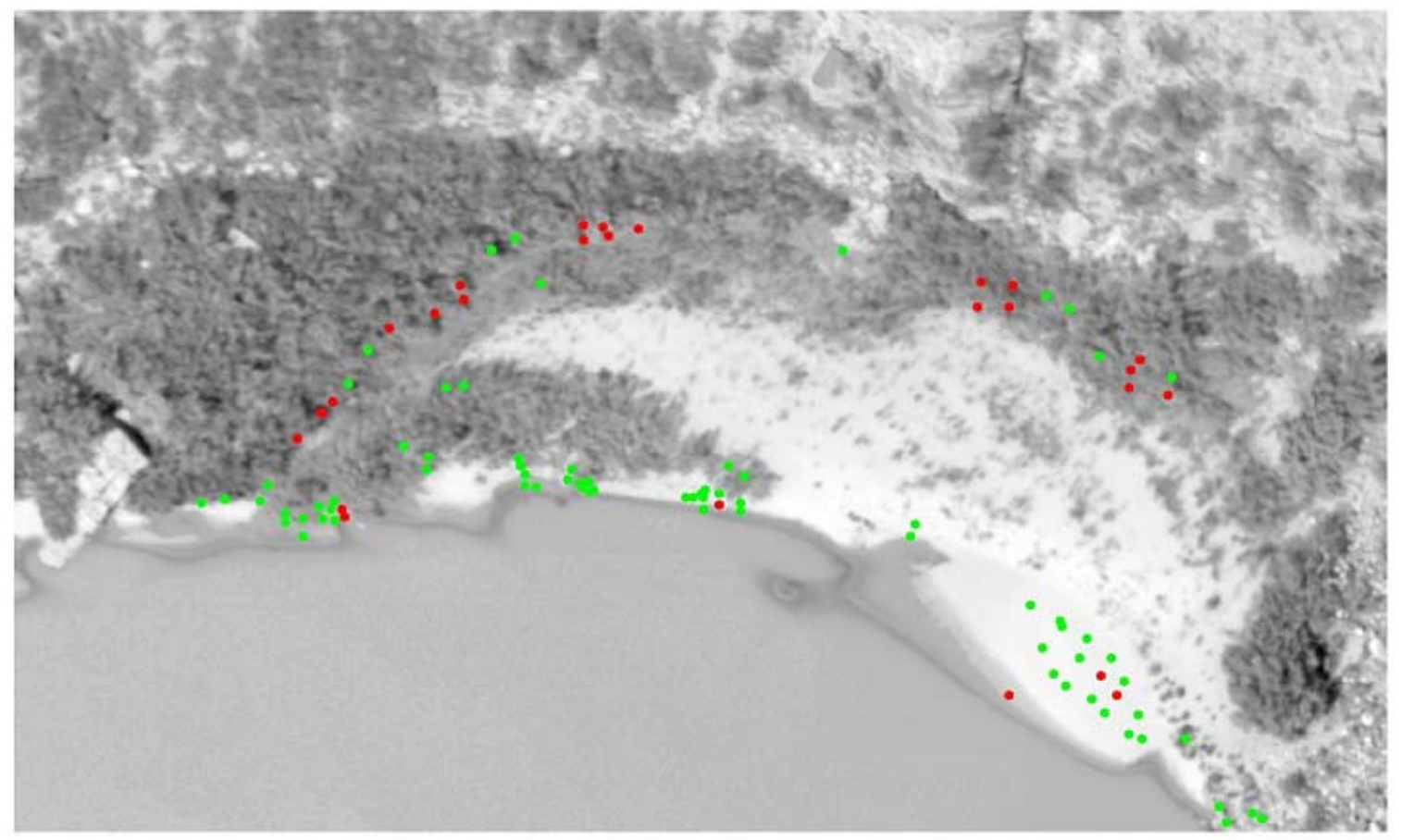

Figure 19. Panchromatic image of RM 43 study area showing locations of elevation errors equal to or greater than $1 \mathrm{~m}$ (red) and errors between 0.5 and $0.99 \mathrm{~m}$ (green) derived from photogrammetric analysis of the $10-\mathrm{cm}$ CIR image data. 


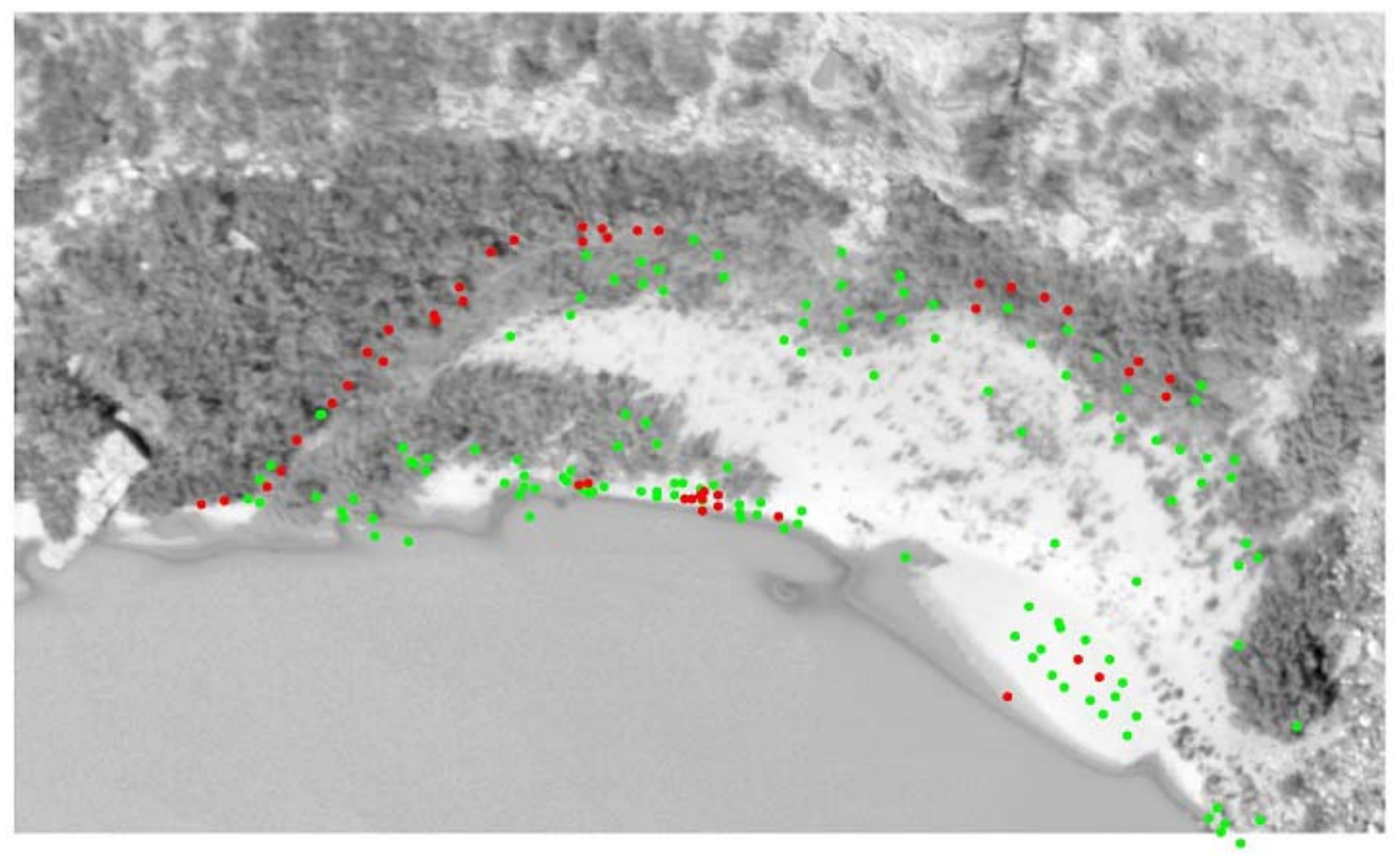

Figure 20. Panchromatic image of RM 43 study area showing locations of elevation errors equal to or greater than $1 \mathrm{~m}$ (red) and errors between 0.5 and $0.99 \mathrm{~m}$ (green) derived from photogrammetric analysis of the $16-\mathrm{cm}$ ( 40 micron scan) true-col or image data. 


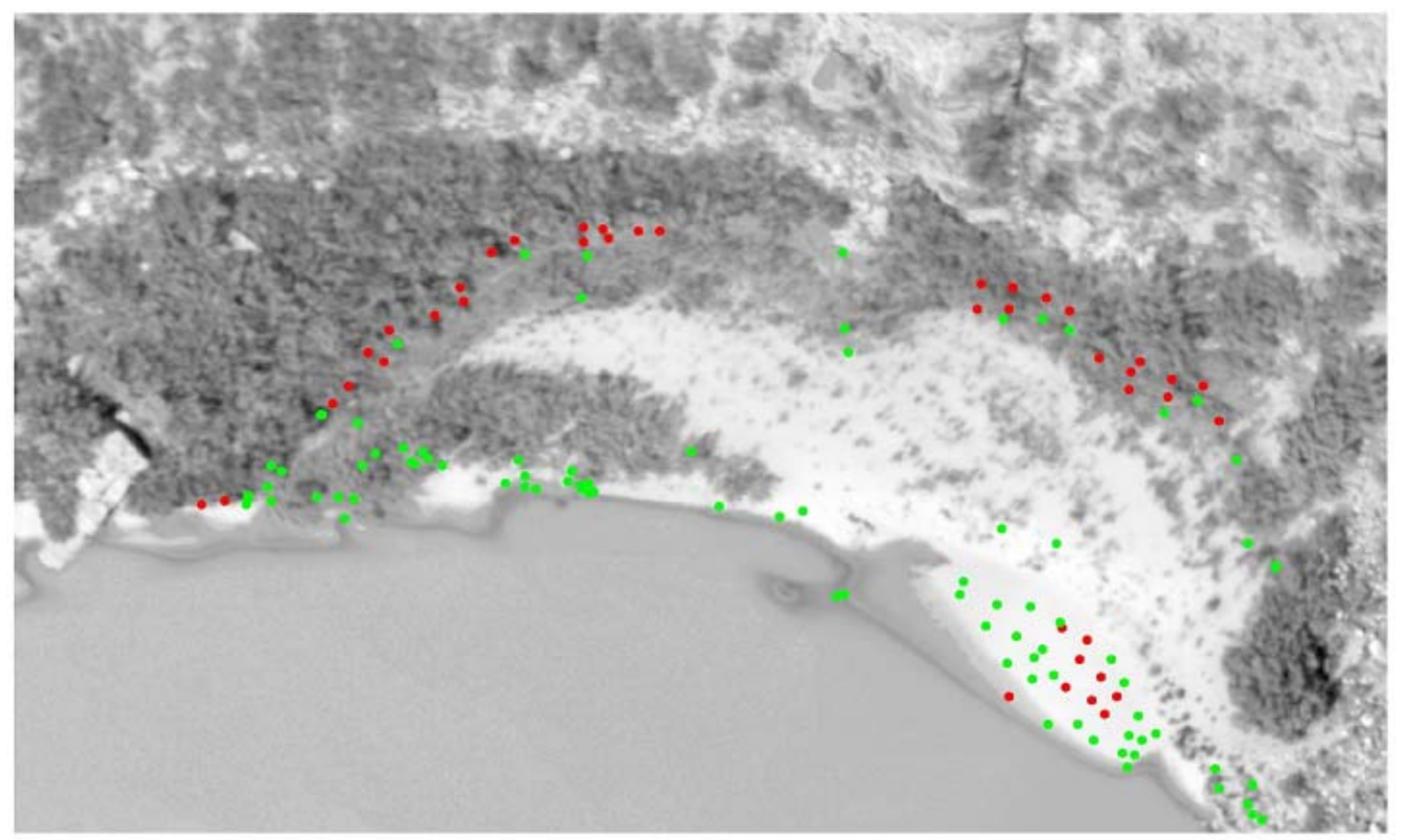

Figure 21. Panchromatic image of RM 43 study area showing locations of elevation errors equal to or greater than $1 \mathrm{~m}$ (red) and errors between 0.5 and $0.99 \mathrm{~m}$ (green) derived from photogrammetric analysis of the $8-\mathrm{cm}$ ( 20 micron scan) true-color image data. 


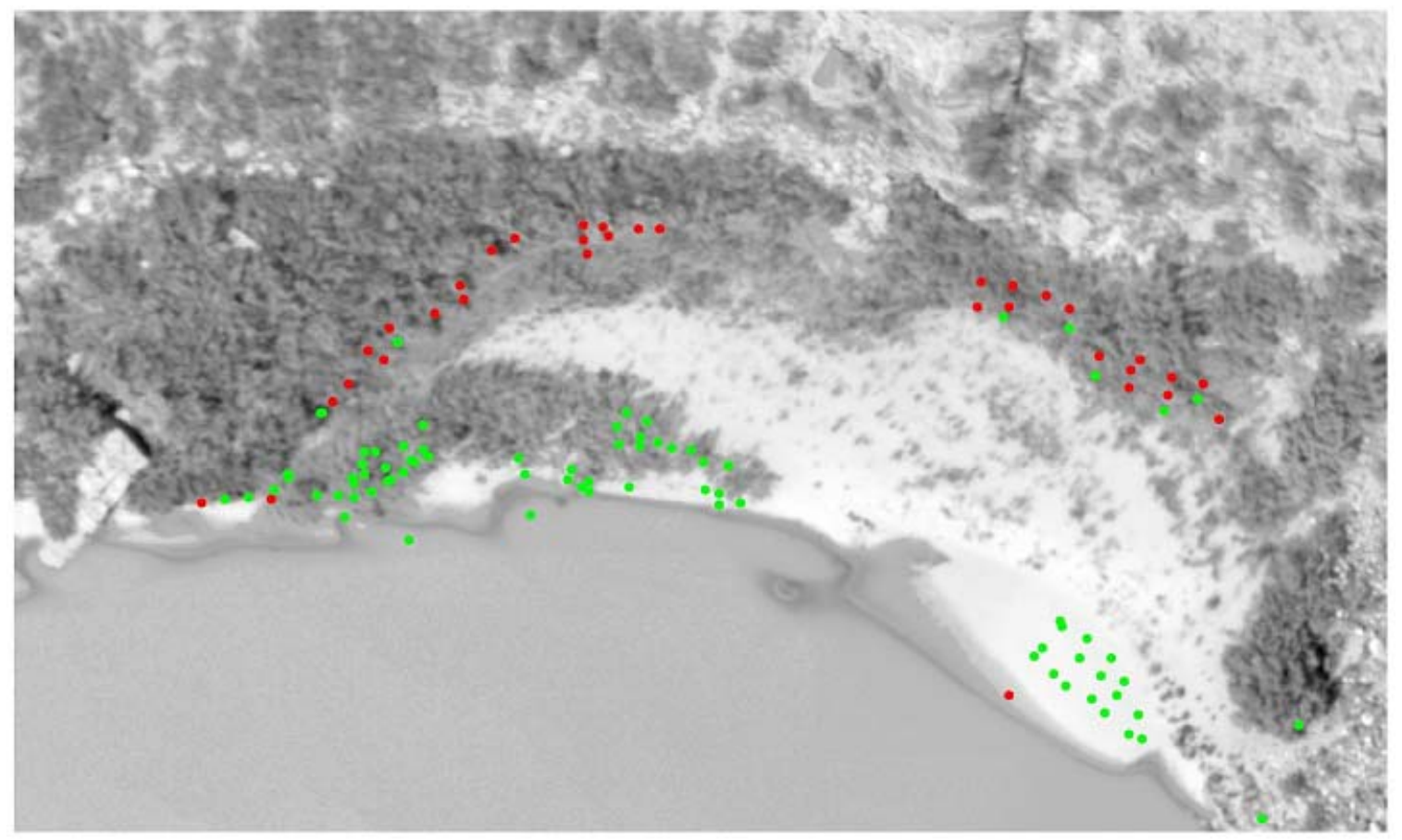

Figure 22. Panchromatic image of RM 43 study area showing locations of elevation errors equal to or greater than $1 \mathrm{~m}$ (red) and errors between 0.5 and $0.99 \mathrm{~m}$ (green) derived from photogrammetric analysis of the $6-\mathrm{cm}$ ( 15 micron scan) true-color image data. 


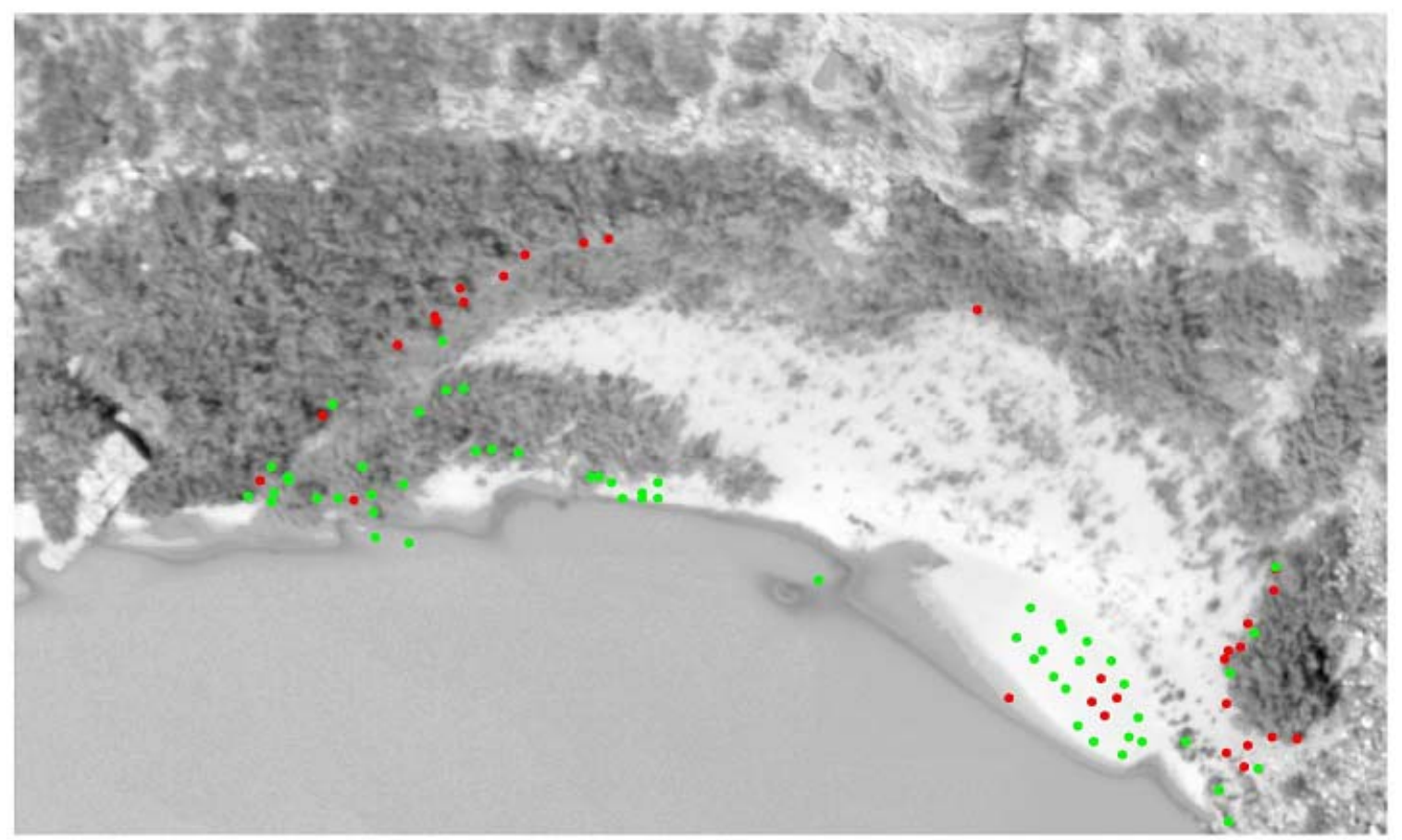

Figure 23. Panchromatic image of RM 43 study area showing locations of elevation errors equal to or greater than $1 \mathrm{~m}$ (red) and errors between 0.5 and $0.99 \mathrm{~m}$ (green) derived from photogrammetric analysis by $\mathrm{PWT}$ of the $6-\mathrm{cm}$ true-color image data. 


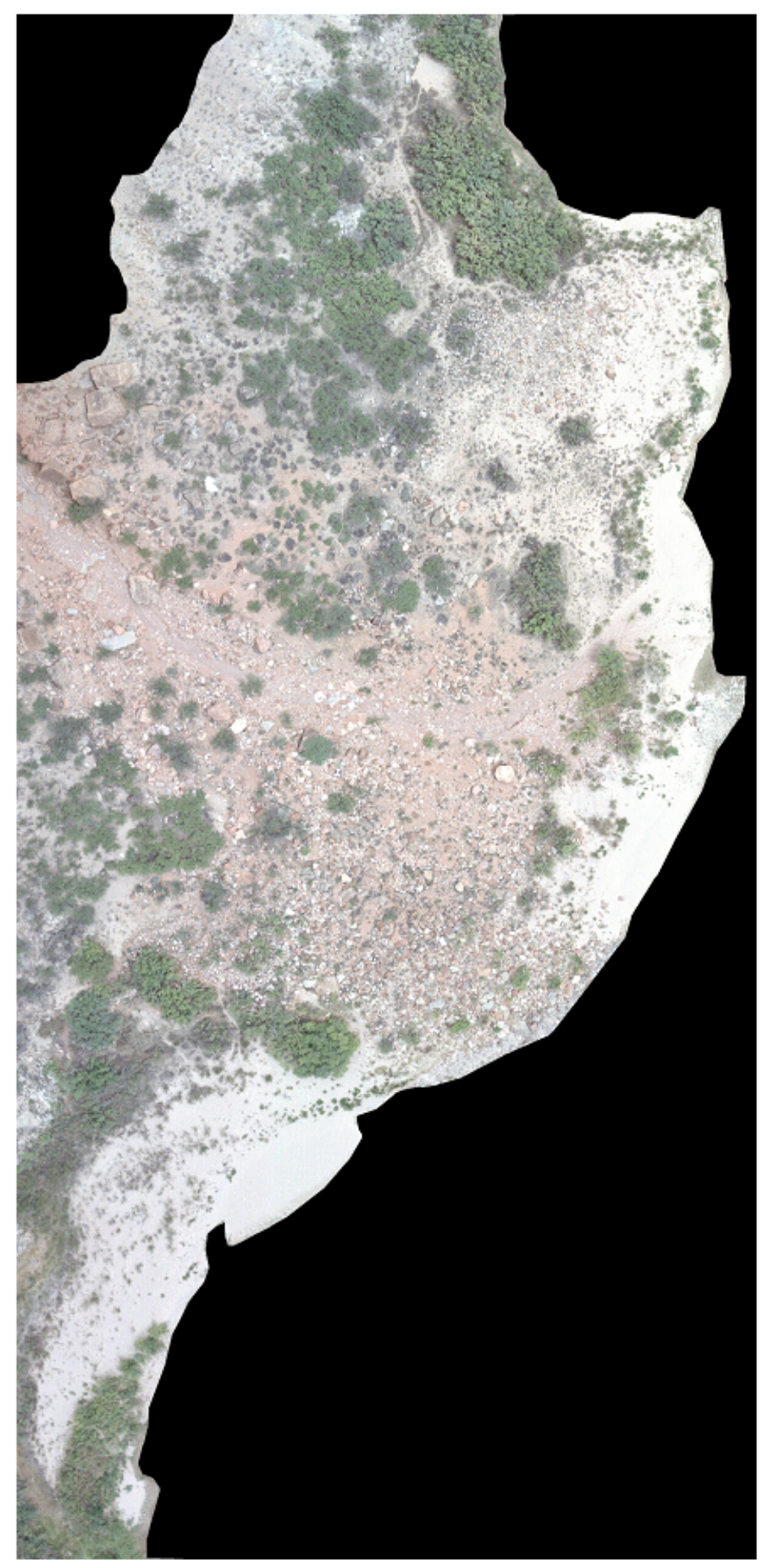

Figure 24. True-color image of RM 43 study area, which has vegetated and bare sand bars separated by a large debris flow. Water and bedrock walls have been digitally masked from this image. Vegetation appears as shades of green, sand bars are white, and the debris flow has shades of brown and red. 


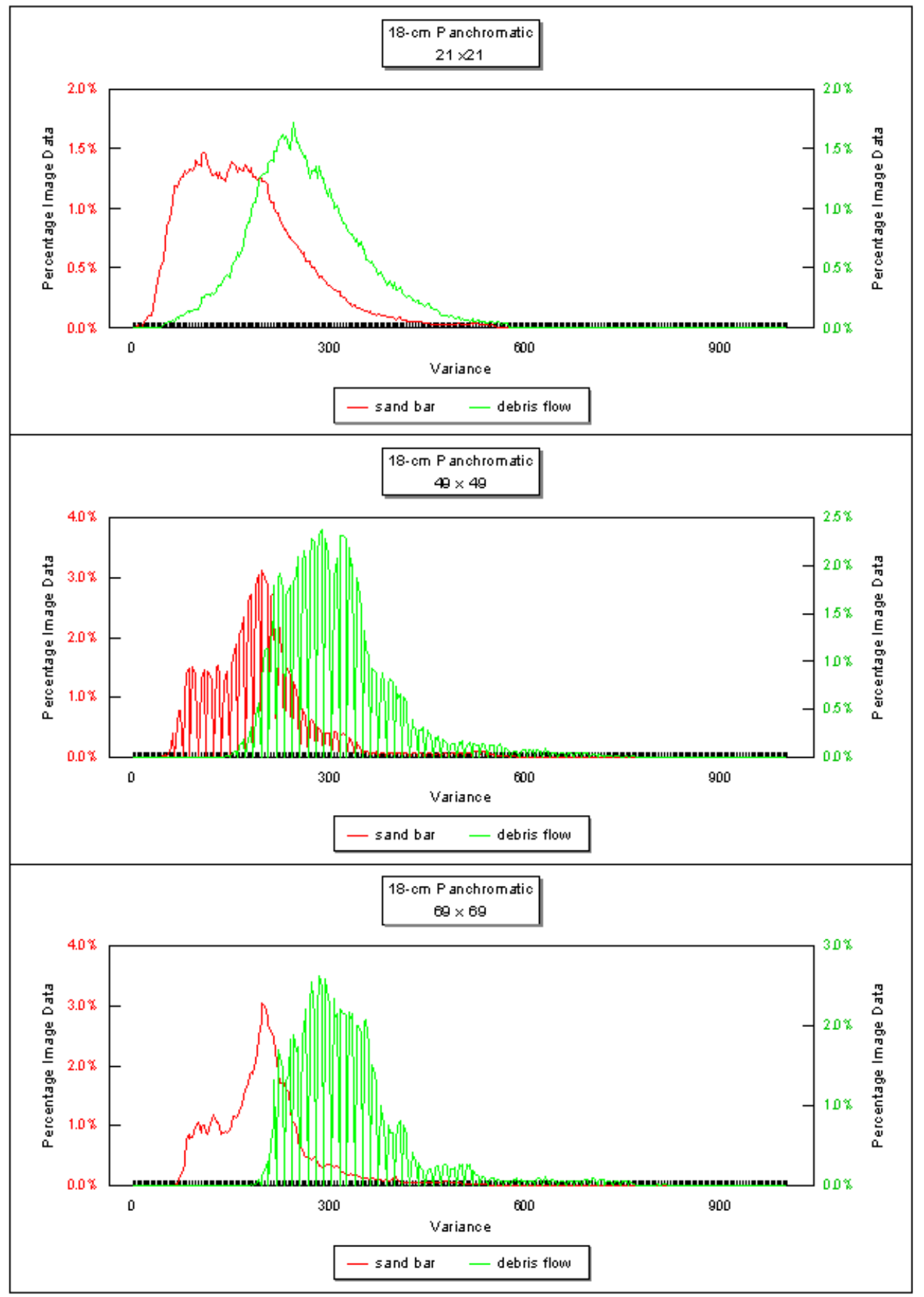

Figure 25. Degree of textural separation provided by panchromatic image data over a range of variance filter sizes. The filter sizes $(\mathrm{n} \times \mathrm{n})$ are picture-element dimensions of the digital filter. 


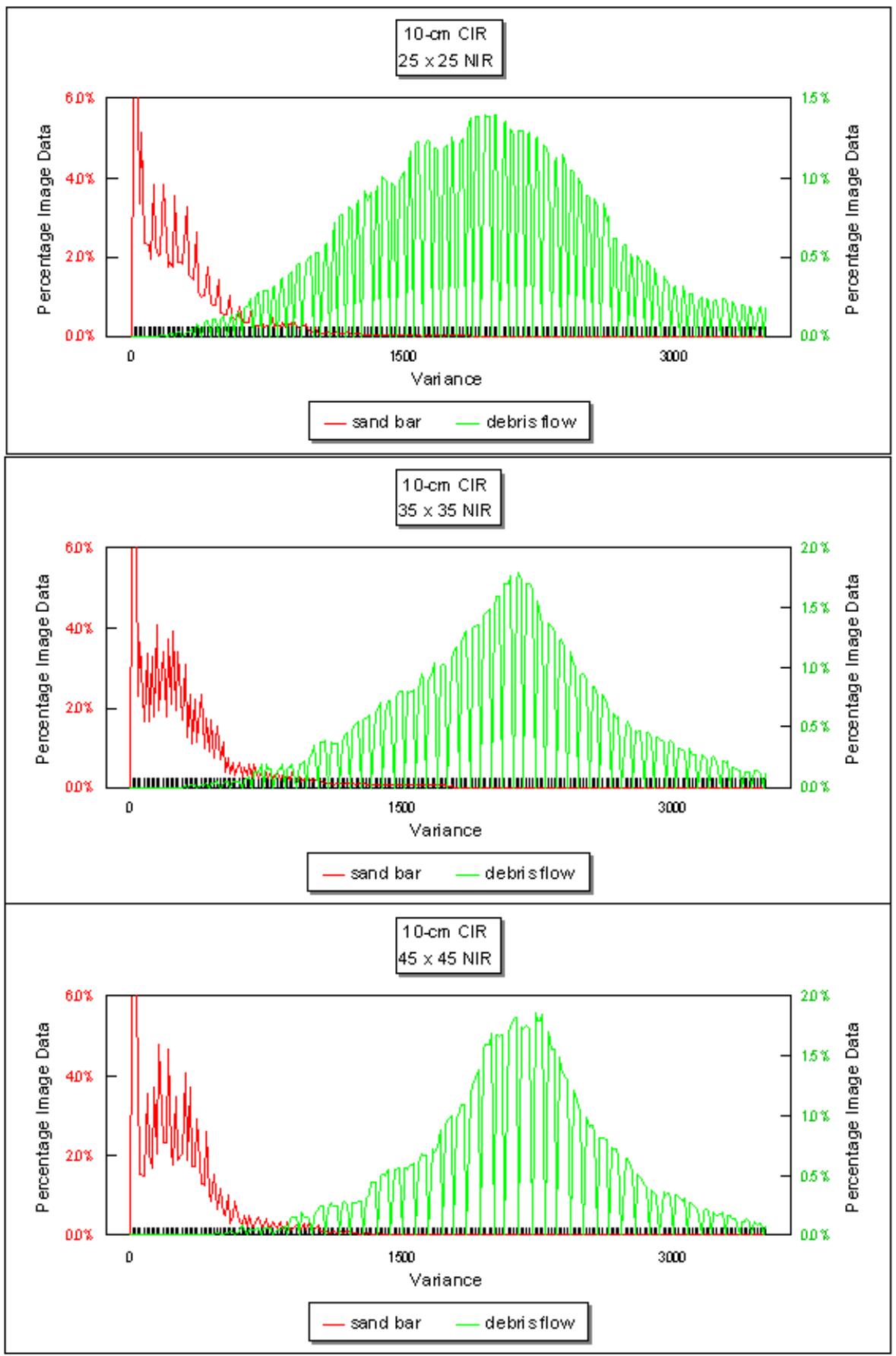

Figure 26. Degree of textural separation provided by $10-\mathrm{cm}$ CR image data over a range of variance filter sizes. The filter sizes $(\mathrm{n} \times \mathrm{n})$ are picture-element dimensions of the digital filter. 


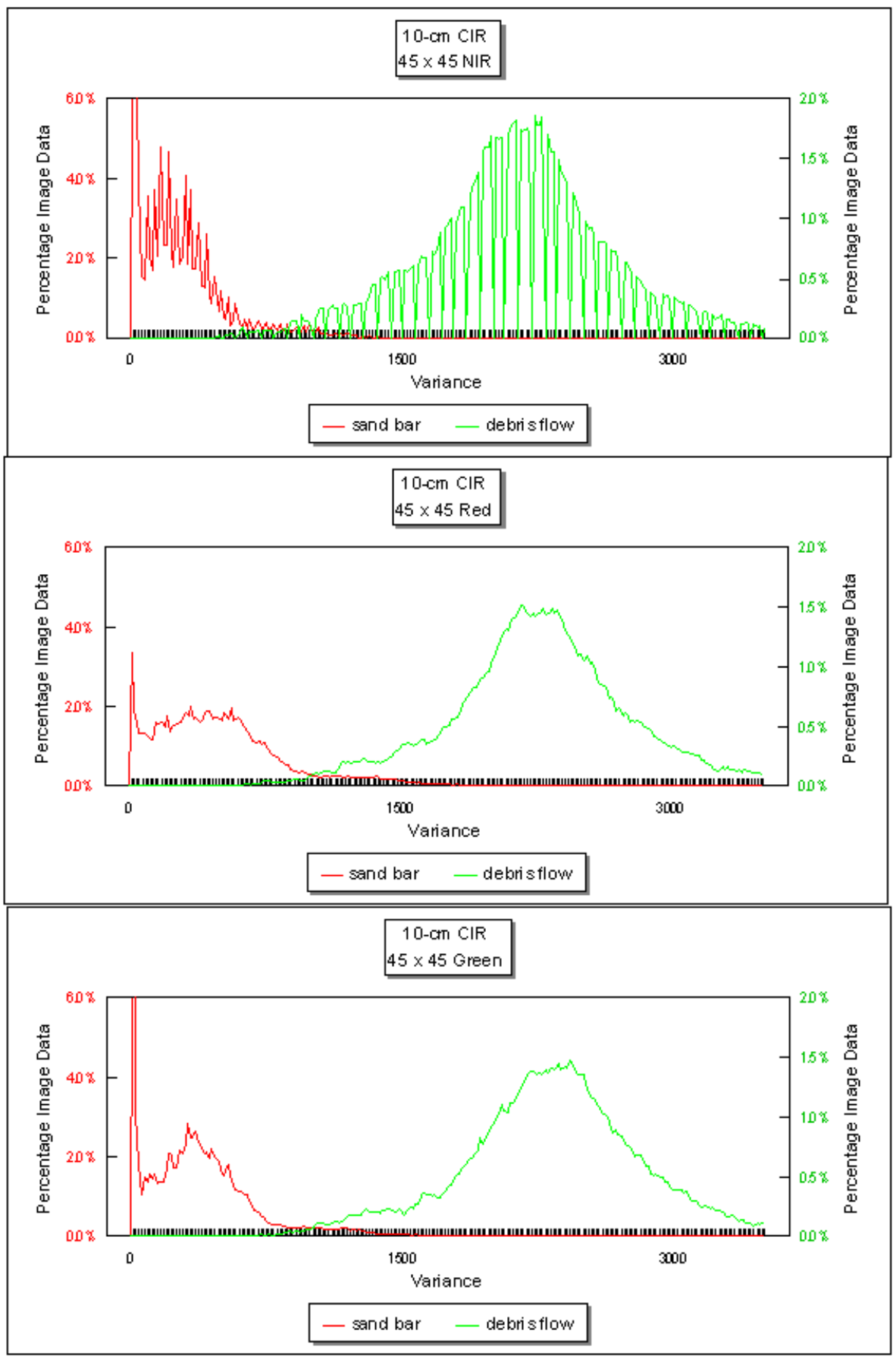

Figure 27. Degree of textural separation provided by different CIR bands for a specific variance filter size. The filter size $(n \times n)$ is the picture-element dimension of the digital filter. 


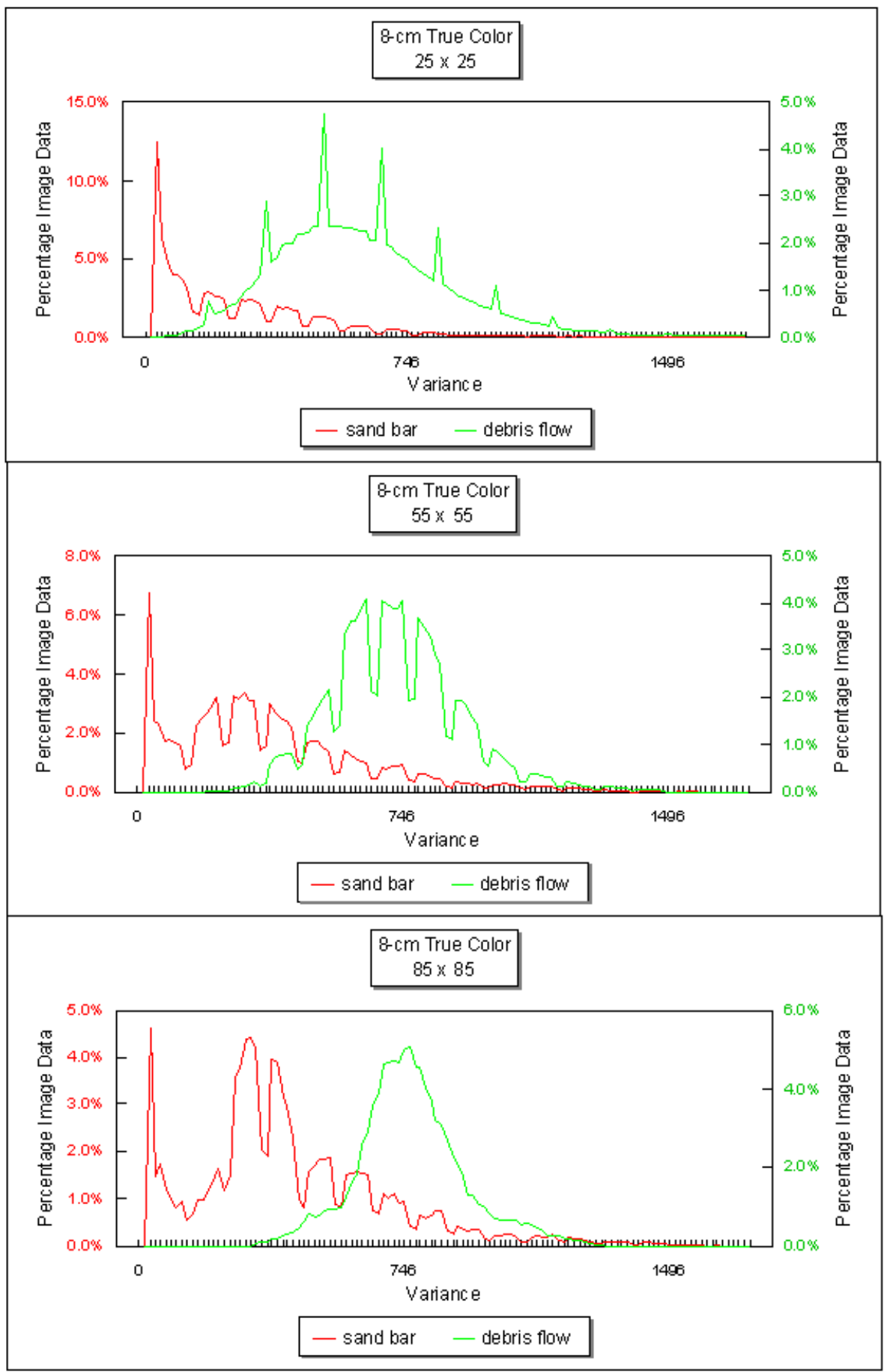

Figure 28. Degree of textural separation provided by true-color image data over a range of variance filter sizes. The filter sizes $(\mathrm{n} \times \mathrm{n})$ are picture-element dimensions of the digital filter. 


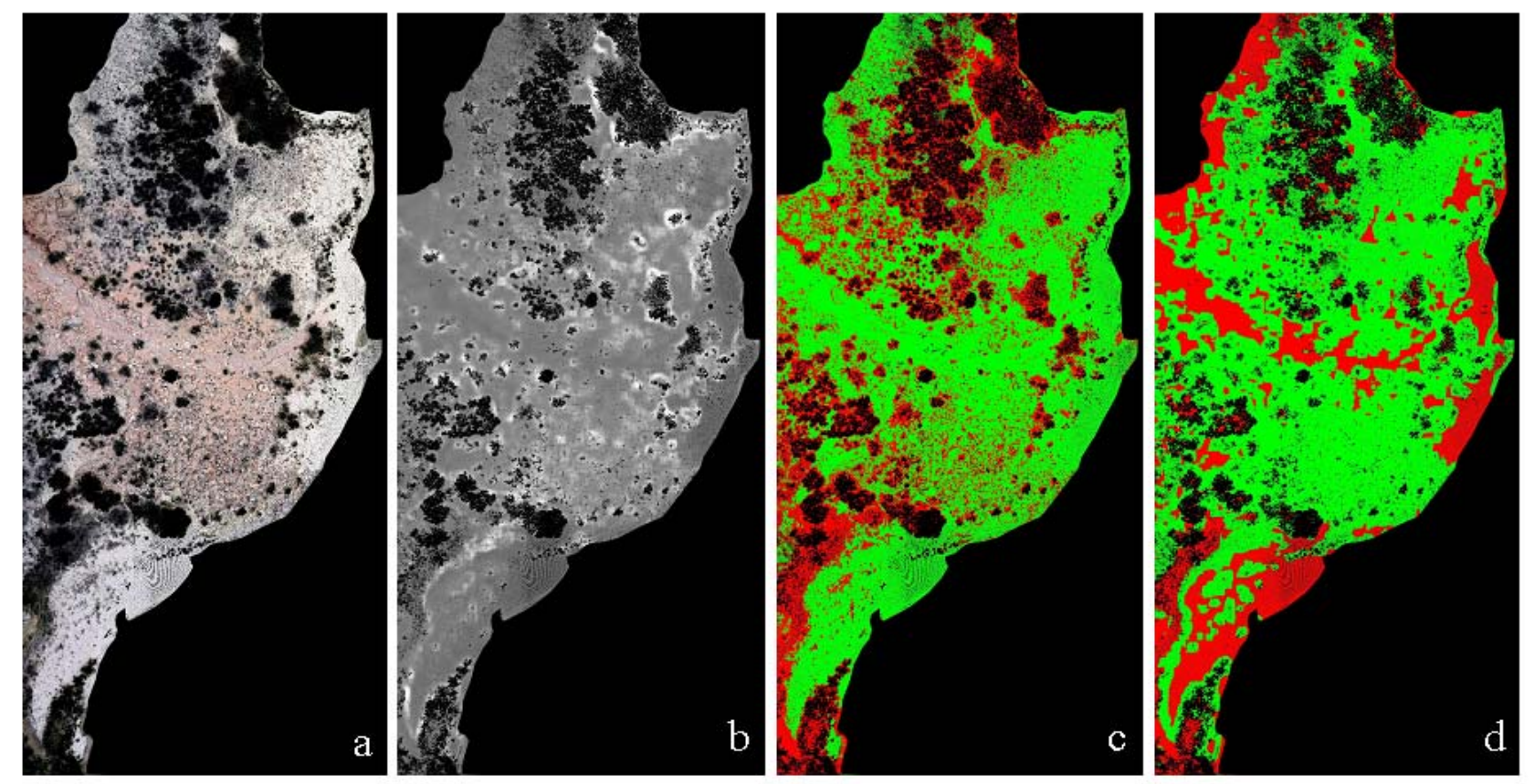

Figure 29. Minimum distance supervised classifier applied to just the true-color color data (a) produced the sand-bar and debris-flow map shown in (c) and applied to both true-col or color (a) and texture (b) data produced the sand-bar and debris-flow map shown in (d). Vegetation, water, and bedrock walls were removed from (a) before classification. 


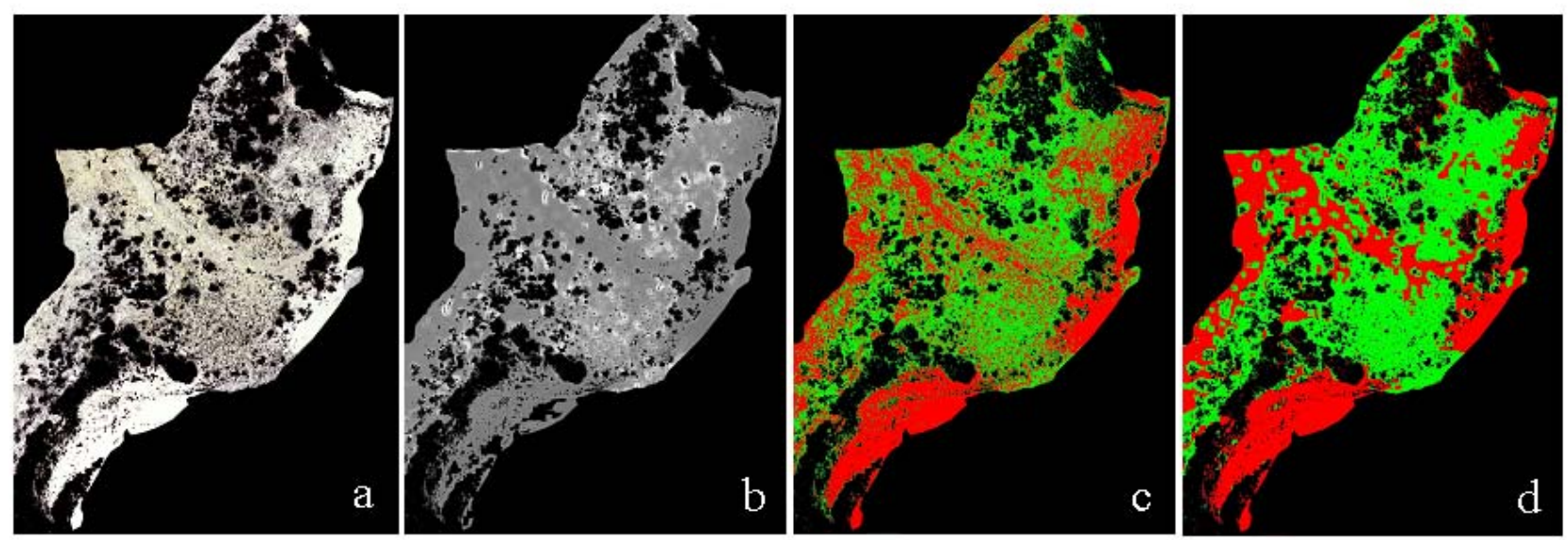

Figure 30. Minimum distance supervised classifier applied just to the CIR color data (a) produced the sand-bar and debris-flow map shown in (c) and then applied to both CIR color (a) and texture (b) data produced the sand-bar and debris-flow map shown in (d). Vegetation, water, and bedrock walls were removed from (a) before classification. 